\title{
Thiol-Ene Click Inspired Late-stage Modification of Long-chain Polyurethane Dendrimers
}

\author{
Dhruba P. Poudel and Richard T. Taylor* \\ Department of Chemistry and Biochemistry, Miami University, 501 E High Street, Oxford, Ohio 45056s
}

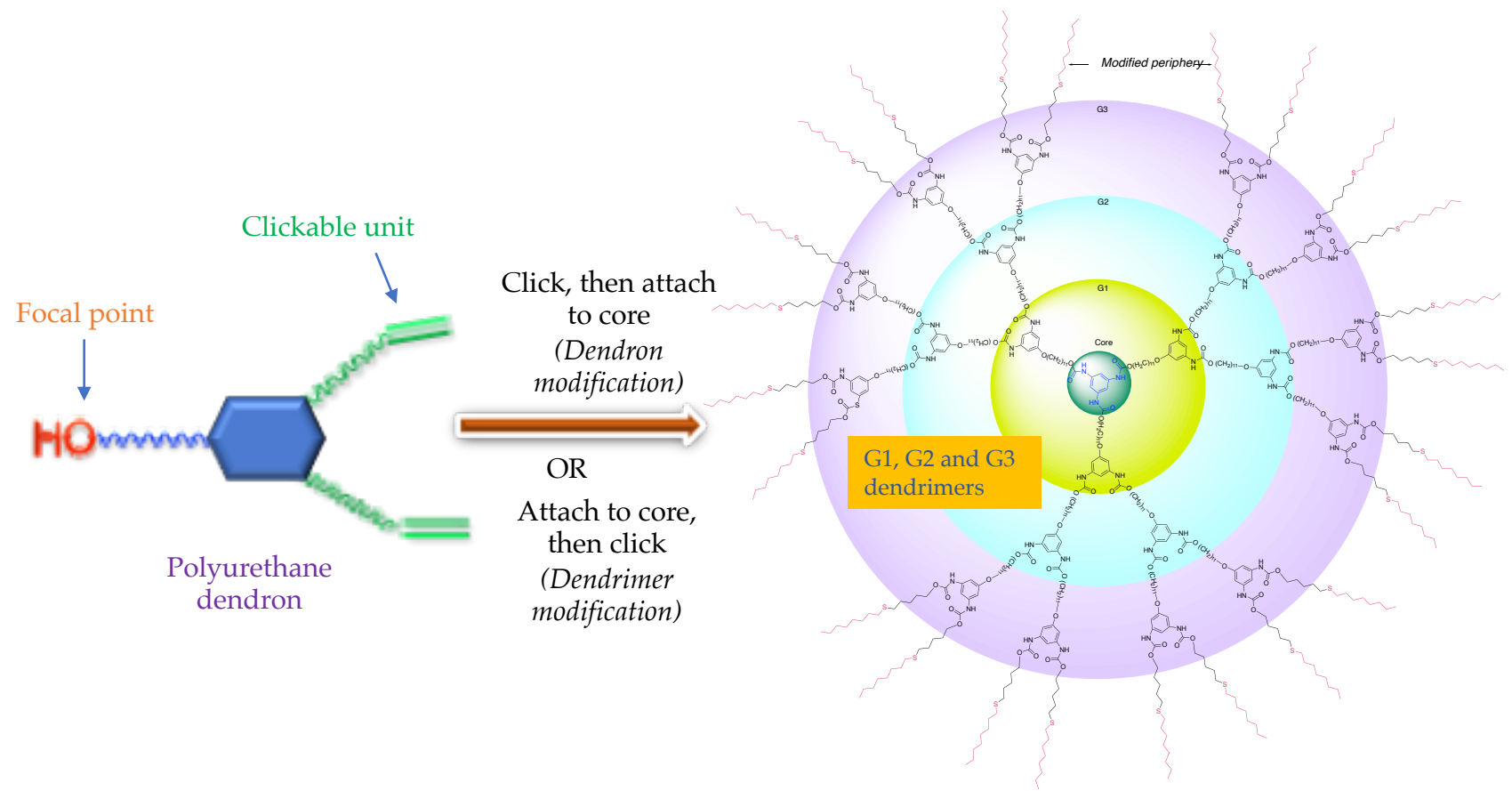

\begin{abstract}
Compared to the synthesis of polyurethane polymers, construction of well-defined polyurethane dendrimers is challenging due to the high reactivity of externally added or in-situ formed isocyanates leading to the formation of side products. For this reason, the synthesis of dendritic polyurethanes is limited to very few reports. With primary focus of dendrimer research on the interaction of the periphery and the core, we report the synthesis of a common polyurethane dendron, which allows for late-stage variation of both the periphery and the core. The periphery can be varied simply by installing a clickable unit in the dendron and then attaching to the core and vice-versa. Thus, a common dendron allows for varying periphery and core in just two steps. To accomplish this, protecting group free one-pot multicomponent Curtius reaction was utilized to afford a robust and versatile $\mathrm{AB}_{2}$ type polyurethane dendron employing commercially available simple molecules 5-hydroxyisophthalic acid, 11-bromoundecanol, and 4penten-1-ol. Subsequent late-stage modification of either dendrons or dendrimers via thiol-ene click reaction gave surfacefunctionalized alternating aromatic-aliphatic polyurethane homodendrimers to generation-three (G3). The dendrons and the dendrimers were characterized by NMR, mass spectrometry, and FT-IR analysis. A bifunctional $\mathrm{AB}_{2}$ type dendritic monomer demonstrated this approach's versatility that can either undergo a thiol-one click or attachment to the core. This approach enables the incorporation of functionalities at the periphery and the core that may not withstand the dendrimer growth for the synthesis of polyurethane dendrimers and other dendritic macromolecules.
\end{abstract}

\section{INTRODUCTION}

Dendrimers are highly branched multivalent, star-shaped polymeric macromolecules. ${ }^{1-4}$ These monodispersed dendritic polymers exhibit wide applications in the field of catalysis, sensing, molecular electronics, photonics, fluorescence, and therapeutics. ${ }^{5-19}$ After Tomalia's first report on poly(amidoamine) (PAMAM) dendrimers in $1985,{ }^{20}$ many research groups have reported the synthesis dendritic macromolecules using ether, ester, carbosilane, amide, and alkyne linkages. ${ }^{21-33}$ Nevertheless, very few have reported the synthesis of dendrimers having urethane linkage. It is noteworthy that, as of now, SciFinder ${ }^{\mathbb{B}}$ reveals less than 100 references showing the entry of polyurethane dendrimers, which is negligible as compared to the references reported on polyurethane polymers (more than 340,000). This data indicates that polyurethane dendrimers ${ }^{34}$ have not been 
studied extensively, which discloses both tremendous opportunities and significant challenges in the field of dendrimer chemistry. The construction of a well-defined architecture of a polyurethane dendrimer is challenging due to isocyanates' high reactivity. ${ }^{35}$ Pleasingly, the pioneering works published simultaneously in 1993 by two research groups established the synthetic routes to polyurethane dendrimers. The first route described by Spindler and Fréchet ${ }^{36,37}$ used isocyanate chemistry. In contrast, the second route described by Kumar and Ramakrishnan ${ }^{38}$ employed an isocyanate-free approach to synthesize polyurethane dendrimers. Following these pioneering works, a few more dendritic polyurethanes have been reported. ${ }^{39-46}$ Recently, Nasar and coworkers have reported synthesis of hyperbranched polyurethanes and polyurethane dendrimers based on blocked isocyanate chemistry. ${ }^{47-52}$

However, the dendrimers have been synthesized equally via well-established convergent and divergent methods; the convergent method involves a small number of reactions per molecule during the coupling and activation dendrons. ${ }^{53}$ This provides greater structural control than with divergent protocol. First reported by Hawker and Fréchet for the synthesis poly(phenyl benzyl ether) dendrimers, ${ }^{54}$ convergent method ensures precise placement of functional groups throughout the dendritic structure that enables the synthesis of functional macromolecules. Though several dendrimers are reported recently employing the convergent method of synthesis, ${ }^{25,31,55-72}$ there are very few reports on polyurethane dendrimers using this method. ${ }^{40,73-75}$

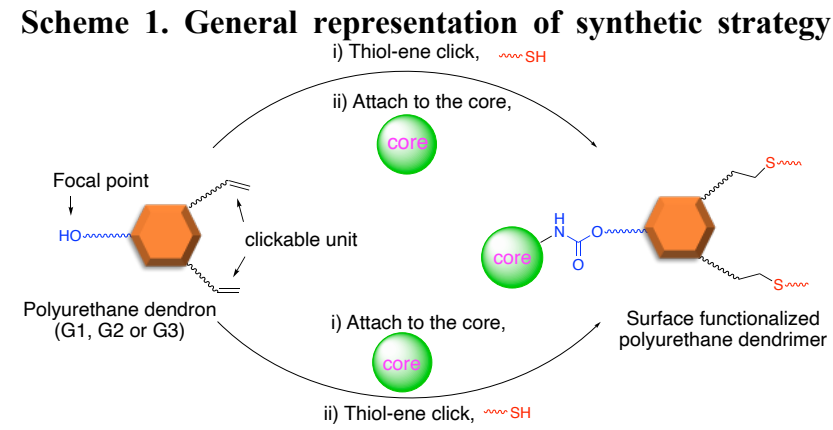

Thiol-ene click reaction, one of the idealized click reactions, is most frequently photoinduced, proceeds with quantitative yield in presence of small concentration of benign catalyst, undergoes with rapid reaction rate, insensitive to moisture, and yields a single stereoselective product. ${ }^{76,77}$ For this reason, thiol-ene click reactions have been widely exploited for synthesis, functionalization, and postmodification/surface modification of dendrimers abd for the formation of cross-linkages in hyperbranched macromolecules. ${ }^{51,78-107}$ Nevertheless, this powerful tool far from its application in the field of polyurethane chemistry. There are only two reports of thiol-ene click reaction employed for the synthesis of hyperbranched aliphatic polyurethanes. ${ }^{108,109}$ To the best of our knowledge, the use of thiol-ene click reaction has not been reported previously.

Our group reported the convergent synthesis of polyurethane dendrimers having dodecyl end groups, using a protection-deprotection strategy two decades ago..$^{110,111}$
Herein, we report on a fast, efficient, and protecting-group free approach to synthesize polyurethane dendrimers to the third generation (G3) using the convergent method. A common polyurethane dendron was synthesized utilizing a one-pot multicomponent Curtius reaction, ${ }^{12,113}$ which allowed for late-stage modification of both the periphery and the core. Using this approach, while the periphery can be varied simply by installing a clickable unit in the dendron followed by its attachment to the core, the convergent method allows for varying the core itself. Thus, a common dendron allows for varying the periphery and the core in just the final two steps. Commercially available 5-hydroxyisophthalic acid, 4-penten-ol, and 11-bromoundecanol were subjected to Curtius reaction to furnish an $\mathrm{AB}_{2}$ type common polyurethane dendron. The subsequent late-stage modification of either dendron or dendrimer via thiol-ene click reaction gave surface-functionalized alternating aliphatic-aromatic polyurethane homodendrimers. As shown in Scheme 1, an $\mathrm{AB}_{2}$ type dendritic monomer can either undergo a thiol-ene click followed by attachment to the core or vice-versa to yield post-modified dendrimers. Previously, we demonstrated this strategy in detail concerning generation-one (G1) dendrimers. In this work, we extend our previous approach to synthesize the polyurethane dendrimers to G3.

\section{RESULTS AND DISCUSSION}

Synthesis of linking agent and core. Commercially available 5-hydroxyisophtalic acid $\mathbf{1}$ was used as a building block to synthesize generation-one dendritic wedge (G1W) ene (or simply a dendron), whereas unprotected 5-hydroxy-1,3diacyldiazide 4 was utilized as a linking group or branching point to afford G2 or G3 dendron (Scheme 2). Linking group 4, a white amorphous solid, was synthesized in a three-step sequence starting from 1 with an overall yield 79\%, where 1 was esterified using methanol followed by nucleophilic substitution with hydrazine and treatment with sodium nitrite under acidic medium. To synthesize a trifunctional core $\mathbf{6}$, 1,3,5-benzenetricarbonyltrichloride was treated with sodium azide forming acyl azide at room temperature, which underwent Curtius rearrangement on affording 1,3,5triisocyanatobenzene $\mathbf{6}^{114}$ as needle-shaped crystals on heating ( $87 \%$ yield).

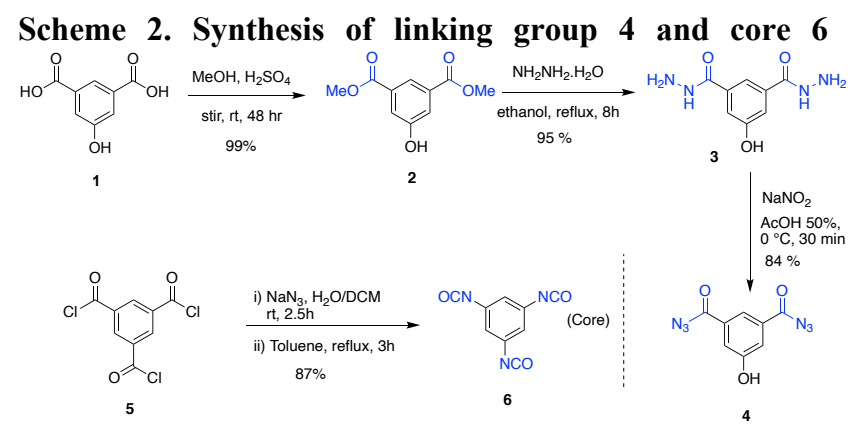

Synthesis of G1 dendrimer. With a core and a building block in hand, we started synthesizing a series of polyurethane dendrimers starting from G1 dendrimer. In this study, 4penten-1-ol and 11-bromoundecanol are used as peripheral and spacer groups, respectively. Accordingly, the G1 dendron required for this operation was prepared from 1 in two steps (Scheme 3). One-pot multicomponent Curtius reaction using 
commercially available starting materials 1, 4-penten-1-ol, and DPPA (diphenylphosphoryl azide) in the presence of a base like $\mathrm{Et}_{3} \mathrm{~N}$ formed an isocyanate on heating due to rearrangement of acyl azide. In situ formed isocyanate was trapped by 4-penten-1-ol to afford phenolic diurethane 7 with $39 \%$ yield over three steps (reaction details in the previous paper-ref to be added). On refluxing 7 with 11bromoundecanol in acetone furnished G1 dendron $(\mathbf{G 1 W})_{\text {ene. }}$. It's noteworthy that the diurethane 7 can also be used as a dendron, but the reactivity is lower than that of alcoholic $\mathrm{OH}$. Also, the installation of the undecyl group increases the solubility even for higher generation dendrons and dendrimers.

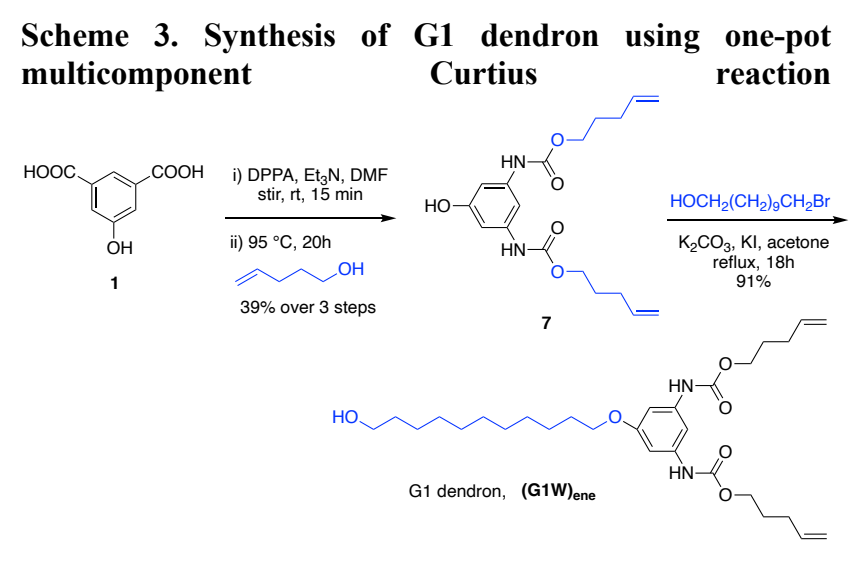

The advantages of this strategy of dendron formation are that the reaction proceeds smoothly in one-pot without the need of separating intermediate isocyanate, and the byproduct, diphenylphosphoric acid, can be separated from the desired product simply using flash chromatography. Our group has already succeeded in preparing polyurethane dendrimers employing this method. ${ }^{111}$ However, the current approach does not require any protection at the focal point of the dendron, which significantly reduces the synthetic steps. Moreover, the current strategy allows one to synthesize dendron on a multigram scale.

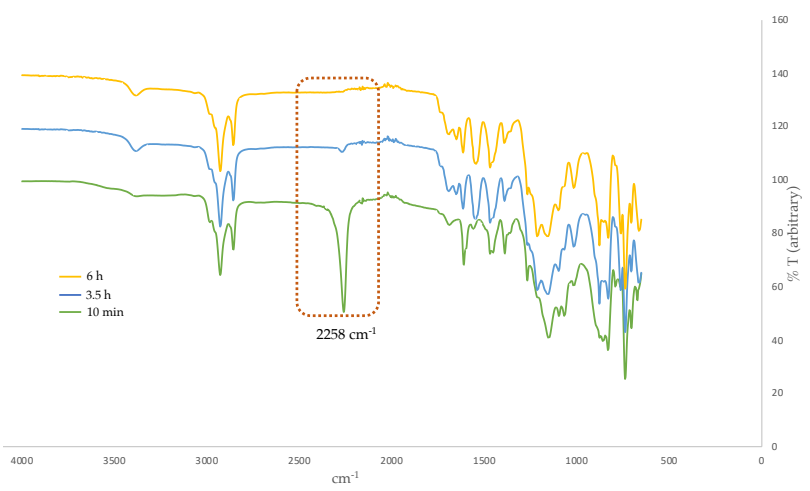

Figure 1. Progress of $\mathrm{BF}_{3} . \mathrm{OEt}_{2}$-catalyzed reaction involving the attachment of dendron to the core monitored by FT-IR spectroscopy. The isocyanate $\mathrm{N}=\mathrm{C}=\mathrm{O}$ stretch at $2258 \mathrm{~cm}^{-1}$ disappears over time.

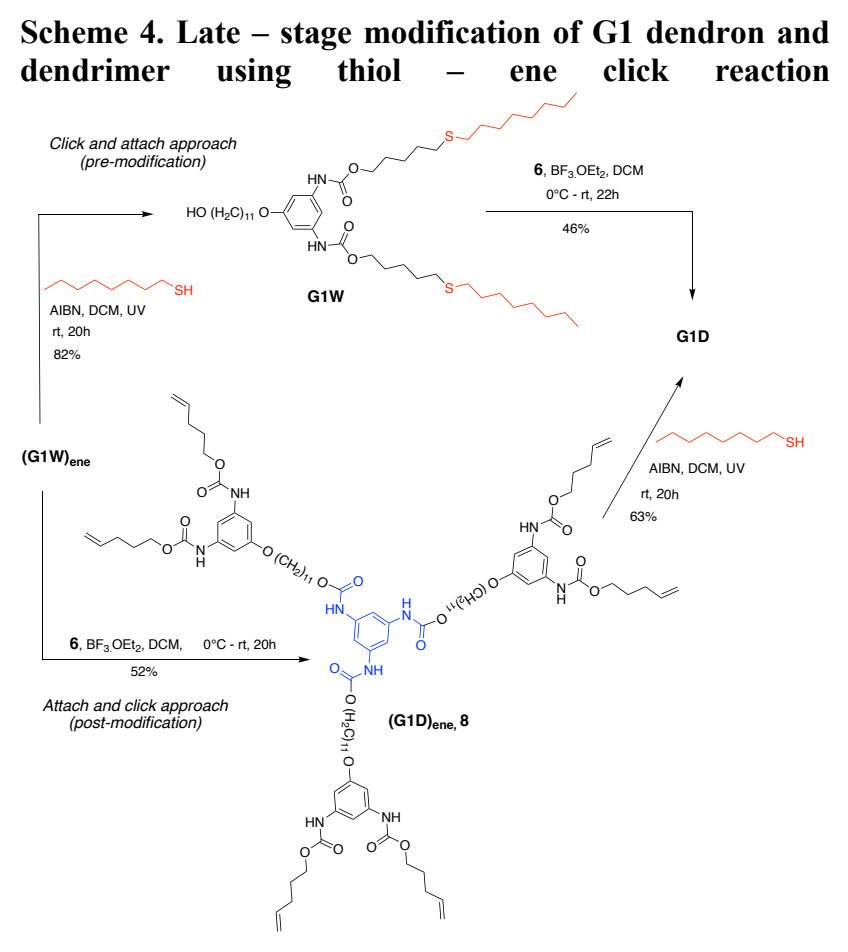

Convergent synthesis has been widely used in the construction of functional macromolecules because it permits to modification of dendrons both at focal points and at the chain ends. Moreover, this approach allows post derivatization of peripheral groups without disturbing the core and repeating units' functionality ${ }^{53}$ Exploiting this theme, we previously demonstrated our late-stage modification strategy's versatility by synthesizing G1 dendrimers using thiol-ene click chemistry. ${ }^{76}$ As shown in Scheme 4, dendrimer G1D can be constructed via two different routes - i) click and attach approach (pre-modification), and ii) attach and click approach (post-modification)- starting from dendron (G1W)ene. Our previous method of dendron formation allows us to change both the periphery and core in just two steps. The peripheral groups can be changed by installing a different clickable unit, whereas a different core can be used during the dendron's attachment to it.

Synthesis of G2 and G3 dendrimers. A convergent synthesis is a stepwise assembly of building blocks or monomer units leading to different generation dendrons' formation. Subsequent attachment of a dendron to the core moiety results in a dendrimer with well-defined architecture. As depicted in Scheme 5, growth of higher generation dendritic wedges commenced with coupling $\mathbf{1}$ with G1 dendron $(\mathbf{G 1 W})_{\text {ene }}$ under Curtius reaction conditions using DPPA as an azide source, and $\mathrm{Et}_{3} \mathrm{~N}$ as a base gave $\mathrm{G} 2$ phenolic dendron 9. However, the yield of this reaction was significantly lower than that of 7 (Scheme 3). Such low yield could be attributed partially to the less reactivity of larger attacking nucleophile (G1W) ene compared with 11bromoundecanol and partially to the side product, diphenyl phosphoric acid produced from DPPA during the reaction. Our attempt to an efficient synthesis of 9 was unsuccessful using $\mathrm{OH}$ protected $\mathbf{1}$ as a linking group, i.e., 5- 
acetoxyisophthalic acid, because we lose the acetate group within

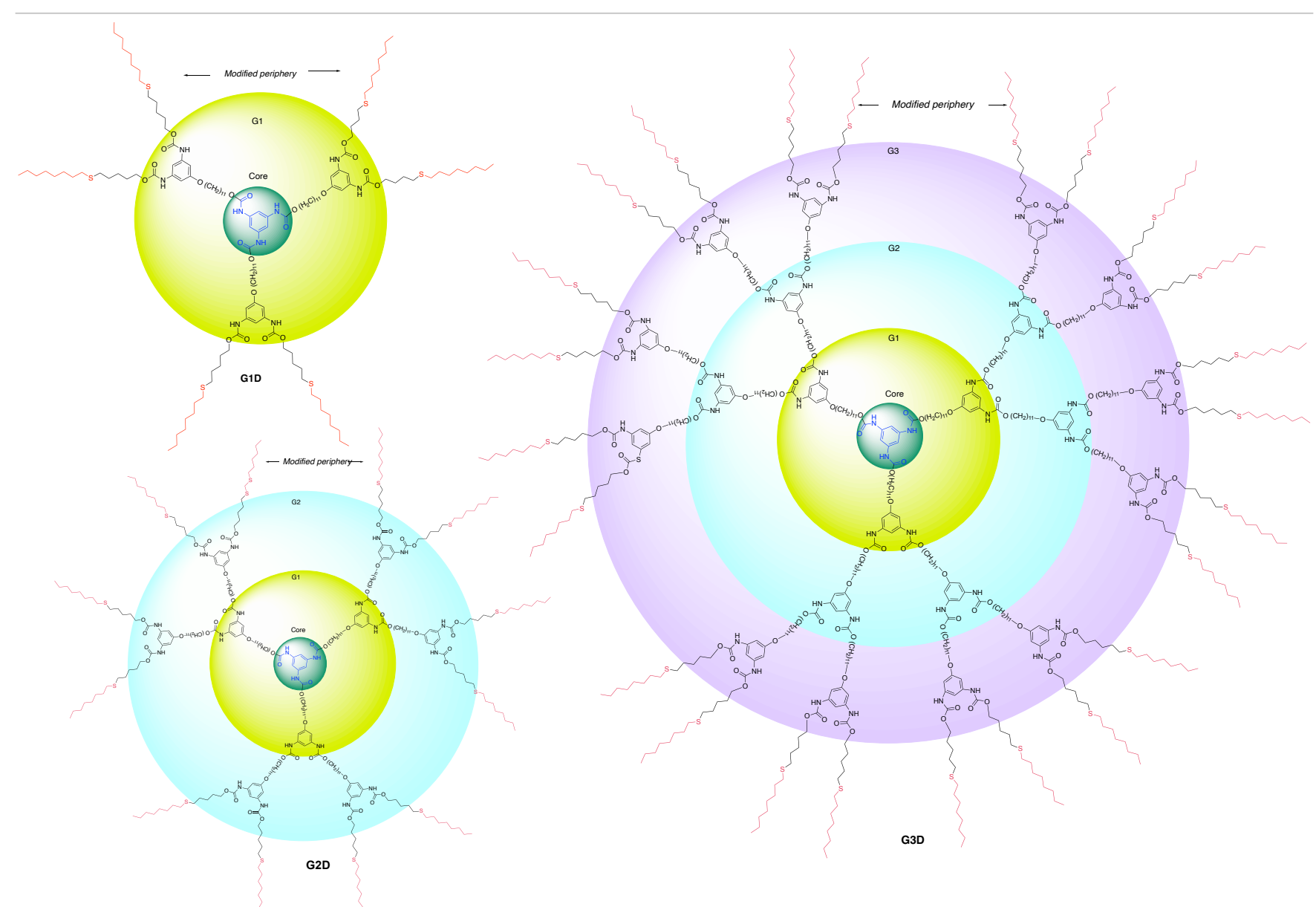

Figure 2. Structure of synthesized G1, G2, and G3 dendrimers showing modified periphery.

an hour on heating at $80{ }^{\circ} \mathrm{C}\left(\mathrm{Et}_{3} \mathrm{~N}\right.$ catalyzes the deprotection). To overcome these difficulties, we synthesized $\mathbf{4}$ as the linking group with a free $\mathrm{OH}$ group on it (Scheme 2), which undergoes Curtius reaction without any catalyst to form 9 with good yield.

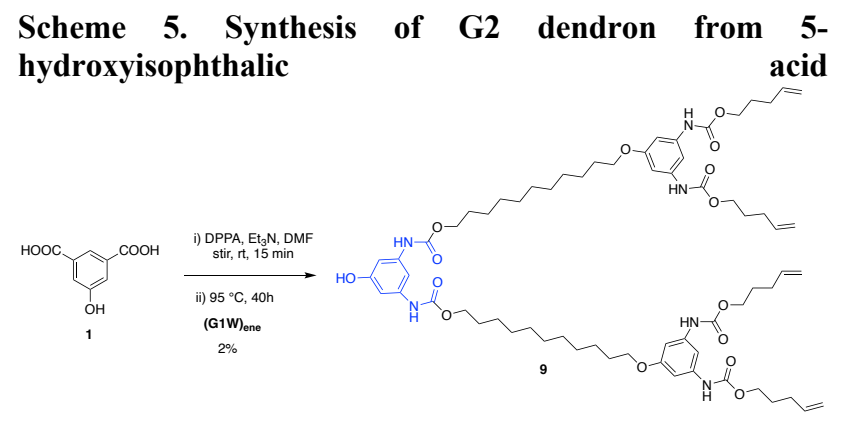

Having optimized the proper reaction conditions, we started coupling of G1 dendron (G1W) ene with linking agent 4 that preceded smoothly on heating under at $95{ }^{\circ} \mathrm{C}$ Curtius reaction conditions in DMF to afford G2 phenolic urethane 9. G2 dendron $(\mathbf{G 2 W})_{\text {ene }}$ with pentene periphery was produced when 9 was heated with 11-bromoundecanol, a spacer group used in this study. In situ formed isocyanate during Curtius rearrangement could be activated by adding a Lewis acid like $\mathrm{BF}_{3} . \mathrm{OEt}_{2}$ as a catalyst, however, it did not accelerate the formation of product because of solvent (DMF) coordinating with catalyst. Moreover, a base like $\mathrm{Et}_{3} \mathrm{~N}$ as a catalyst would render unprotected phenolic $\mathrm{OH}$ more nucleophilic, leading to the phenolic attack on in situ formed isocyanate, thereby increasing the side products' yield. Therefore, we carried out this particular reaction without any catalyst, and better results were obtained over a longer time. Thiol-ene functionalization of peripheral alkene moieties with 1-octanethiol in the presence of 2,2'-azobis(2-methylpropionitrile) (AIBN) freeradical initiator under UV light formed G2 dendron G2W containing thioether functionality in end groups. In its final step, periphery-modified $\mathbf{G 2 W}$ was attached to the trifunctional core $\mathbf{6}$ in the presence of Lewis acid catalyst $\mathrm{BF}_{3} . \mathrm{OEt}_{2}$ to afford generation-two dendrimer G2D as highly viscous, transparent gel. Figure 1 shows FT-IR monitoredprogress of $\mathrm{BF}_{3}$. OEt $\mathrm{Ot}_{2}$-catalyzed reaction involving attachment of dendron to the core. 
Iteration of Curius reaction followed by undecyl group attachment (steps i and ii, Scheme 6) to the so-formed phenolic wedge $\mathbf{1 0}$ produced generation-three dendron $(\mathbf{G 3 W})_{\text {ene }}$ starting from generation-two dendritic wedge $(\mathbf{G 2 W})_{\text {ene }}$ and linking group 4. Peripheral pentene moieties of this G3 dendron was subjected to thiol-ene click conditions as in G1 and G2 steps to form a modified G3 dendron G3W, which was then attached to trifunctional core 6 to generate G3 dendrimer, G3D.

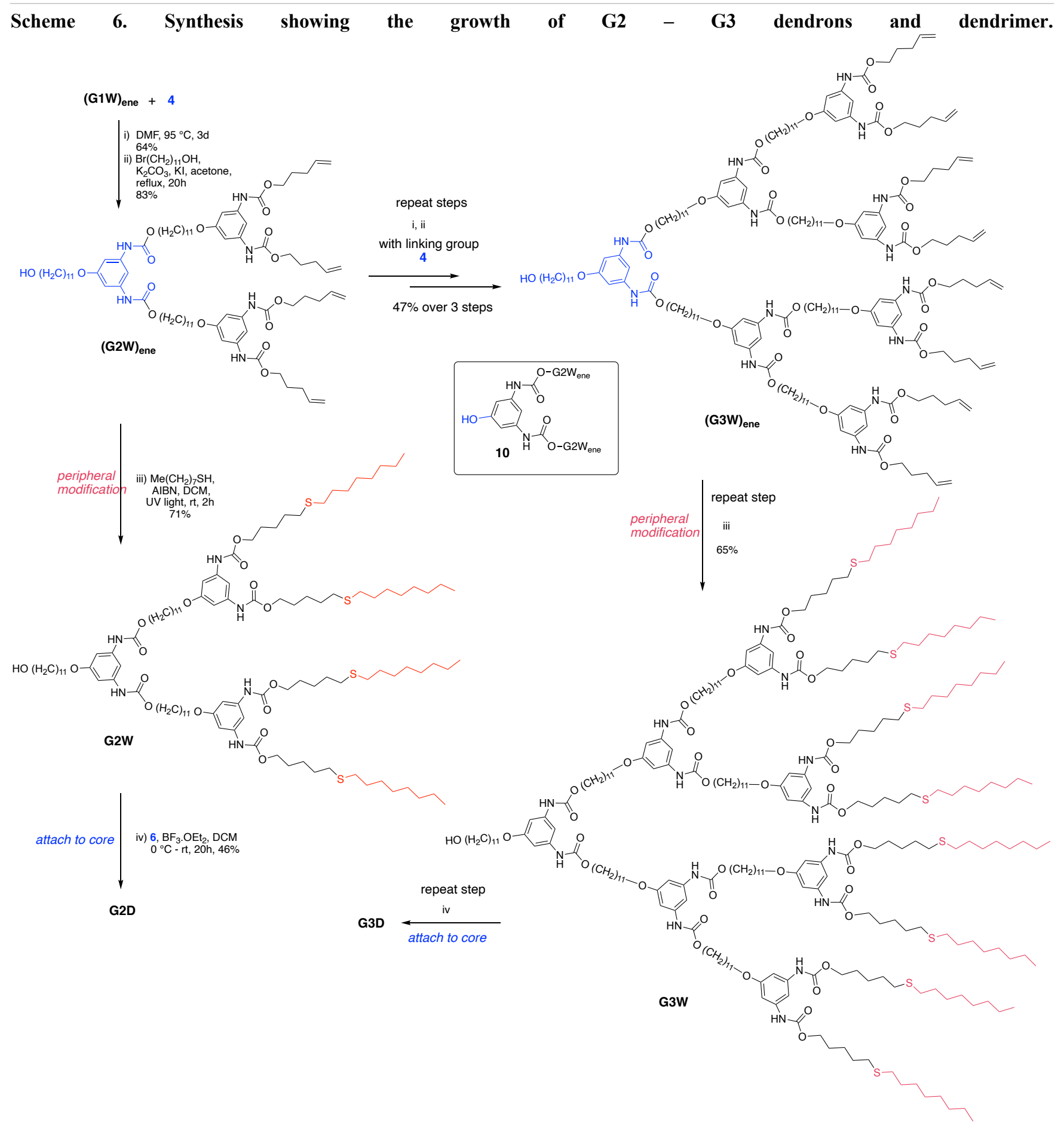

Our strategy allows for the growth of a new generation dendron in every two steps, thereby furnishing G3 dendron (with an alkene periphery in this case) only over six steps. The first of the two steps involve Curtius reaction that generates urethane linkage via nucleophilic attack of alcohol on in situ formed isocyanate (obtained from internal rearrangement of acyl azide), and the second step involves attachment of undecyl group as a tail. Both of these reactions do not require protection - deprotection and the products can be purified easily using silica gel chromatography. The advantage of using a clickable periphery is that these groups remain unreactive during the growth of dendron. 
As shown in Scheme 6, we opted click and attach approach to synthesize G2 and G3 dendrimers. The reasoning behind this can be explained in terms of yield and the complexity of the reaction. Our study showed that the click-then-attach approach proceeds with better yields than that of the attachthen-click approach (Scheme 4). Attachment of dendron to a trifunctional core involves the same number of reactions per molecule in both approaches; however, end group modification by thiol-ene click during attach-then-click approach requires a large number of reactions per molecule to undergo completion. Such transformations suffer from the same complications as divergent synthesis as the
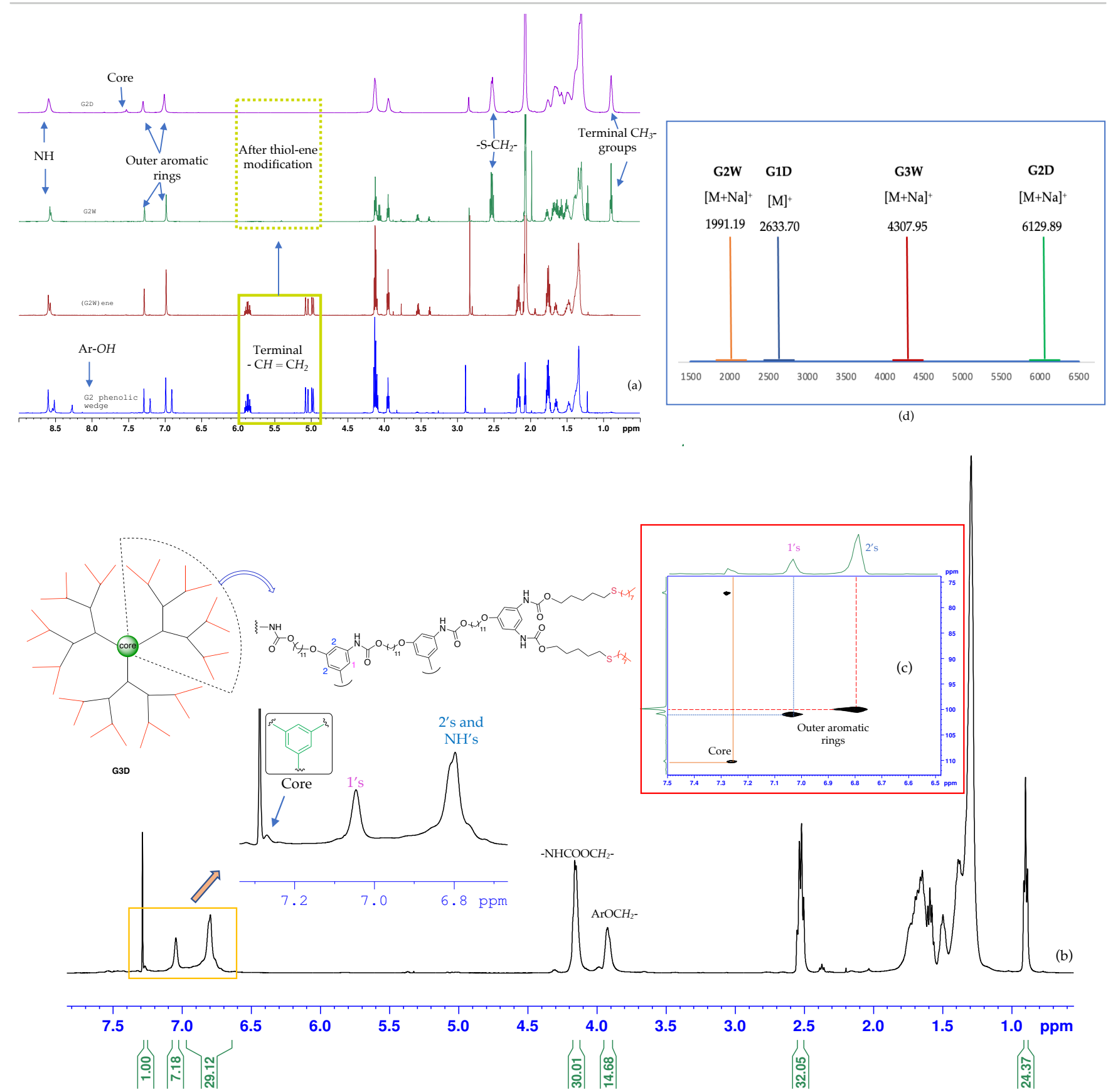

Figure 3. (a) Representative ${ }^{1} \mathrm{H}$ NMR spectra (stacked) showing G2 phenolic wedge $\mathbf{9},(\mathbf{G} 2 \mathbf{W})_{\text {ene, }}, \mathbf{G} 2 \mathbf{W}$, and G2D respectively from bottom to top, (b) ${ }^{1} \mathrm{H}$ NMR spectrum of G3D: integrals in full spectrum show the one-third portion of this $\mathrm{C} 3$ symmetric molecule whereas the expanded region depicts aromatic protons of both core and peripheral groups, (c) a portion of HSQC of G3D showing heternonuclear ${ }^{1} \mathrm{H}$ ${ }^{13} \mathrm{C}$ coupling at aromatic region, and (d) MALDI-TOF spectra of G1-G3 denrons and dendrimers (NMR spectra were recorderd in $500 \mathrm{MHz}$ spectrometer at $298 \mathrm{~K}$ using $\mathrm{CD}_{3} \mathrm{COCD}_{3}$ as deuterated solvent). 
multiplicity of end groups increases with higher generation resulting in incomplete or side reactions or even degradation of branches, which burdens the purification of the dendrimer.

Characterization of dendritic structures. Thiol-ene click modified polyurethane dendrimers G1D-G3D were first characterized by one-dimensional multinuclear $\left({ }^{1} \mathrm{H}\right.$ and $\left.{ }^{13} \mathrm{C}\right)$ as well as two-dimensional (2D) homonuclear and heteronuclear NMR spectroscopy. As shown in the ${ }^{1} \mathrm{H}$ NMR spectra (Figure 3 and S18, S19, and S27), over $0.0 \mathrm{ppm}$, the peaks of protons assigned to G1D-G3D remain unchanged, indicating the identical structures of the dendrimers. However, these peaks became broader with increasing generations, possibly because the protons became nonequivalent, going from the first to the third-generation dendrimer. In the stacked ${ }^{1} \mathrm{H}$ NMR of $\mathrm{G} 2$ dendrimeric structures (Figure 3a), the peaks at $\sim 5.9-5.0$ ppm assigned to the terminal alkenes disappeared, ultimately indicating that the thiol-ene reaction went successfully to completion. This formtion of new peaks - a quartet at $\sim 2.5 \mathrm{ppm}$ and a triplet at $\sim 0.9 \mathrm{ppm}$ assigned to $-\mathrm{SCH}_{2}$ - and the terminal $-\mathrm{CH}_{3}$ groups, respectively - further supports the completion of thiol-ene reaction. Attachment of dendrons $\mathbf{G 1 W}-\mathbf{G} \mathbf{3} \mathbf{W}$ to the trifunctional core was evidenced by the appearance of a new ${ }^{1} \mathrm{H}$ peak at the aromatic region (figure 3 a purple spectrum and $3 \mathrm{~b}$ ). Expanded region of figure $3 \mathrm{~b}$ shows aromatic protons' peaks of G3D where a more shielded broad peak at $\sim 6.8 \mathrm{ppm}$ is assigned to both NH's and aromatic protons ortho to aryl ethers. In contrast the most deshielded peak at $\sim 7.3 \mathrm{ppm}$ accounts for aromatic protons of the core. Over $0.0 \mathrm{ppm},{ }^{1} \mathrm{H}$ NMR of G1-G3 dendrimers were also characterized by two-dimensional homonuclear and heteronuclear NMR spectroscopy. Figure 3c shows an aromatic region of two-dimensional heteronuclear single quantum coherence (HSQC) spectroscopy of G3D where more downfield peak $(\sim 7.25$ ppm, $110 \mathrm{ppm}$ ) corresponds to the aromatic proton of the trifunctional core.

Mass spectrometric investigation of polyurethane dendrimers G1D-G3D was performed by matrix-assisted laser desorption/ionization time-of-flight mass spectrometry (MALDI-TOF-MS), which supported the existence of these dendrimers. In the MALDI-TOF-MS spectrum (Figure S3741 ), the peak of $\mathrm{m} / \mathrm{z}=2633.70$ detected was consistent with the theoretical mass of $[\mathrm{G} 1 \mathrm{D}+\mathrm{H}]+$ ion $(\mathrm{m} / \mathrm{z}=2632.70)$. The peak at $\mathrm{m} / \mathrm{z}=6129.89$ detected in the MALDI-TOF-MS spectrum (Figure S..) corresponded to the [G2D+Na]+ ion (theoretical $\mathrm{m} / \mathrm{z}=6125.94$ ). For the polyurethane dendrimer G3D (theoretical mass $=13043.46$ ), the MALDI-TOF-MS spectrum provided unsatisfactory mass data, possibly because the dendrimer absorbed the laser wavelength (355 nm) used in the instrument subsequently fragmenting the coumpond before it gives $[\mathrm{G} 3 \mathrm{D}]^{+}$signal. (As shown in the Figure S51, the G3D has broad absorption from 280-360 nm with an emission maxima at $382 \mathrm{~nm}$, Figure S52).

To further determine the structure of G1D - G3D, we also employed two-dimensional (2-D) diffusion-ordered spectroscopy (DOSY). The observation of a distinct spectral band in the DOSY spectrum (Figure S31-S36) of the dendrimers implied the existence of G1D, G2D, or G3D. Moreover, a gradual decrease in the diffusion coefficient $(D)$ observed $-4.47 \times 10^{-10}($ G1D $), 1.86 \times 10^{-10}($ G2D), and 1.38 $\times 10^{-10}(\mathbf{G 3 D})-$ in the spectrum provided further evidence of a progressive increase in the size of the dendrimers with increasing generations.

Late - stage modification of dendrimers. Also termed as post-synthetic modification, the late-stage modification is a powerful synthetic method to produce functional materials of wide applications. ${ }^{115}$ This approach not only enables the synthesis of a material that cannot be synthesized directly but also ensures the synthesis of combinatorial materials. For example, a library of G1 - G3 polyurethane dendrimers can be produced just in the final two steps using the thiol-ene click reaction followed by attachment to the core. Although the post-synthetic functionalization can be brought both at the focal point ${ }^{116}$ and the periphery of the dendrimers, the modification at the periphery is of particular interest. This is because, with the growing generation of a dendrimer, the core along with repeating units get shielded, and peripheral units are the only means of communication with an external environment. As a result, the properties of the dendrimer solely depends on the peripheral units. Thiol-ene clickinspired orthogonal surface modification of a dendrimer furnishes a dendrimer with different physical and chemical properties. $^{117}$

\section{CONCLUSION}

In summary, we demonstrated a thiol-ene click-inspired, protecting group-free approach towards the convergent synthesis of polyurethane dendrimers. One-pot multicomponent Curtius reaction followed by a spacer group's attachment gave a new generation common dendron in every two-step, which allowed for late-stage modification of both the periphery and the core. As a representative of the proposed approach, thioether surface-functionalized polyurethane G1 dendrimers were synthesized via both 'click then attach' and 'attach then click' approaches using a trifunctional core. Higher generation dendrimers, G2D and G3D, were synthesized employing the 'click then attach' strategy to minimize the incomplete reactions and possible degradations at the periphery that could be associated with the 'attach then click' approach. Access to this type of investigation will contribute to a concise and efficient synthesis of not only the polyurethane dendrimers but also for other dendritic macromolecules. Our ongoing research also involves the synthesis and characterization of dendrimers with alkyne moieties, which undergo late-stage modification using azide-alkyne click chemistry.

\section{EXPERIMENTAL ESCTION}

General information. Starting materials were used as obtained from commercial sources: Sigma Aldrich $\left(\mathrm{NaN}_{3}\right.$, AIBN, 1-octadecanethiol, triethylamine), TCI (4-penten-1-ol, 1-bromoundecanol, benzene-1,3,5-trcicarbonyltrichloride, 1octanethiol, $\mathrm{BF}_{3} \cdot \mathrm{OEt}_{2}$ ), and Alfa Aesar (5-hydroxyisophthalic acid, DPPA). Whereas anhydrous solvents were used in the dendrimer synthesis, DMF (Acros Organics), DCM (Fischer Scientific), and acetone (Acros Organics) were used as received, reagent toluene was used without distillation. Curtius reaction was set in a Carousel reactor, and all other reactions were performed using classical batch process using oil bath (if heat needed). A UV lamp from American Ultraviolet Company (model: PC-100S; $120 \mathrm{~V}, 60 \mathrm{~Hz}, 5$ Amp; S/N: 9902L3669) was used to carry out the thiol-ene click reaction. Melting points were determined using Thermo Scientific MelTemp 3.0 instrument. 
${ }^{1} \mathrm{H},{ }^{13} \mathrm{C}$, and 2D NMR spectra were recorded with a Bruker Advance $500 \mathrm{MHz}$ NMR instrument at 298K. NMR spectra were recorded using either acetone- $d_{6}$ or $\mathrm{CDCl}_{3}$ as a deuterated solvent, and accordingly, the solvent residual peaks were obtained at $\delta 2.05 \mathrm{ppm}$ (qn) and $\delta 7.26 \mathrm{ppm}(\mathrm{s})$ respectively in ${ }^{1} \mathrm{H}$ NMR. In ${ }^{13} \mathrm{C}$ NMR, solvent residual peaks were recorded at $\delta 206.68 \mathrm{ppm}$ (s) and $\delta 29.92 \mathrm{ppm}$ (septet) for acetone- $d_{6}$ and $\delta 77.23 \mathrm{ppm}$ (s) for $\mathrm{CDCl}_{3}$. Coupling constants $(J)$ are given in hertz $(\mathrm{Hz})$ whereas, chemical shifts are given in $\delta$ scale (ppm). Moreover, the multiplicities are indicated as - s (singlet), d (doublet), t (triplet), q (quartet), qn (quintet), or $\mathrm{m}$ (multiplet). IR spectra were obtained from PerkinElmer Spectrum One FT-IR Spectrometer.

HRMS spectra of small molecules, including dendrons, were obtained from FTMS plus CESI mass spectrometer using DCM as a solvent. MALDI of larger molecules was recorded with a Bruker Autoflex 3 instrument using dithranol and ferulic acis as the matrix in positive ion mode.

Purification of compounds was carried out using flash chromatography with irregular silica of $40-60 \mu \mathrm{m}, 60 \AA$. Small scale purification was achieved using auto-column flash cartridges packed with $12 \mathrm{~g}$ or $40 \mathrm{~g}$ silica of $40-75 \mu \mathrm{m}, 60$ $\AA$ (obtained from Sorbtech and Supelco Technologies). Flow rate was $10 \mathrm{~mL} / \mathrm{min}-30 \mathrm{~mL} / \mathrm{min}$. The mobile phase used in these separations was ethyl acetate, hexane, DCM, or a mixture of these solvents.

General procedure of Curtius reaction. Method 1. An oven-dried carousel tube was charged with 5hydroxyisophthalic and a magnetic stirrer. After degassing and backfilling the tube with nitrogen, anhydrous DMF was added. The compound was dissolved completely, followed by the slow addition of $\mathrm{Et}_{3} \mathrm{~N}$ and dropwise addition of DPPA under stirring at ambient temperature. After stirring the solution for $15 \mathrm{~min},(\mathbf{G 1 W})_{\text {ene }}$ was added, and the tube was transferred to carousel reactor maintained at $95{ }^{\circ} \mathrm{C}$. The reaction was monitored with TLC. After $40 \mathrm{~h}$, the solution was cooled to room temperature, diluted 20 times with water, and extracted with EtOAc (3 times). Combined organic layers were washed with water (5 times) and brine (once), concentrated under reduced pressure and purified by flash chromatography.

Method 2. An oven-dried carousel tube was charged with 5hydroxy-1,3-dicarbonyl diazide 4 and a dendron, (G1W)ene or (G2W)ene. After degassing and backfilling the tube with nitrogen, anhydrous DMF was added, and then the solution was transferred to the carousel reactor maintained at $95^{\circ} \mathrm{C}$. The reaction was monitored with TLC. After $72 \mathrm{~h}$, work-up was performed similarly to method 1 .

General procedure of thiol-ene click reaction. The dendron having an alkene periphery was dissolved in anhydrous DCM in a glass vial. 1-Octanethiol (1.1 eq/double bond) and AIBN (0.1 eq/double bond, as a free-radical initiator) were added to the solution. The vial was then capped and placed under a broad spectrum UV lamp under stirring at ambient temperature. After $2 \mathrm{~h}$, the solvent was evaporated, and the crude was purified by flash chromatography.

General procedure of attachment of dendron to the core. An oven-dried RB flask was charged with 1,3,5triisocyanatobenzene and magnetic stirrer. After degassing and backfilling the flask with nitrogen, anhydrous DCM was added via syringe. The flask was then placed under an ice- bath and three drops of $\mathrm{BF}_{3} . \mathrm{OEt}_{2}$ was added. After stirring 10 min, a solution of dendron in anhydrous DCM was added dropwise, and stirring was continued for $10 \mathrm{~min}$. The ice bath was removed, and the stirring was continued for $20 \mathrm{~h}$. The progress of the reaction was monitored using FT-IR observing the isocyanate peak $\left(\sim 2200 \mathrm{~cm}^{-1}\right)$. When the peak disappeared, the stirring was stopped, the solvent was evaporated, and the crude was purified by flash chromatography.

(Synthetic procedure of compounds from 7 to G1D has been reported previously. ${ }^{118}$ )

5- Hydroxy- 1,3- benznedicarbonyl diazide 4. Dimethyl-5hydroxyisophthalte 2 ( $10 \mathrm{~g}, 47.6 \mathrm{mmol}, 1.0 \mathrm{eq})$ was dissolved in ethanol $(100 \mathrm{~mL})$ in a $250 \mathrm{~mL}-\mathrm{RB}$ flask containing a magnetic stir bar. Hydrazine hydrate $(14.65 \mathrm{~mL}, 51 \%, 142.8$ mmol, 5.0 eq) was added, and the mixture was refluxed. The progress of the reaction was checked with TLC (1:1 EtOAc/hexane). After 8h, white solid formed was filtered, washed with cold ethanol, and dried under vacuum overnight to get white powder as product $3(9.54 \mathrm{~g}, 45.4 \mathrm{mmol}, 95 \%$ yield, m.p. $257^{\circ} \mathrm{C}$ ). It was carried to the next step without further purification.

5-Hydroxy-1,3-benzenedicarboxylic acid-1,3-dihydrazide 3 (9.54 g, $45.43 \mathrm{mmol}, 1.0 \mathrm{eq})$ was dissolved in $50 \% \mathrm{v} / \mathrm{v}$ acetic acid $(120 \mathrm{~mL})$ in a $250 \mathrm{~mL}-\mathrm{RB}$ flask containing a magnetic stir bar. The solution was placed at an ice-bath, and $\mathrm{NaNO}_{2}$ ( $9.40 \mathrm{~g}$ in $90 \mathrm{~mL}$ MQ water, $136.29 \mathrm{mmol}, 3.0 \mathrm{eq}$ ) was added dropwise at $0{ }^{\circ} \mathrm{C}$. Stirring was continued for $30 \mathrm{~min}$ at the same temperature. The white solid formed was filtered, washed with cold water, and dried under vacuum to give compound 4 as amorphous white solid (8.86 g, $38.16 \mathrm{mmol}$, $84 \%$ yield). It was pure enough for further reactions. TLC (35\% EtOAc in hexane): $\mathrm{R}_{f}$ 0.46. ${ }^{1} \mathrm{H}$ NMR $(500 \mathrm{MHz}$, $\left.\mathrm{CD}_{3} \mathrm{COCD}_{3}\right): \delta 9.42(\mathrm{~s}, 1 \mathrm{H}, \mathrm{OH}), 8.05(\mathrm{t}, J=1.43 \mathrm{~Hz}, 1 \mathrm{H})$, $7.72(\mathrm{~d}, J=1.45 \mathrm{~Hz}, 2 \mathrm{H}) .{ }^{13} \mathrm{C} \mathrm{NMR}\left(125 \mathrm{MHz}, \mathrm{CD}_{3} \mathrm{COCD}_{3}\right)$ : $\delta$ 171.0, 158.2, 132.7, 121.0, 120.8. HRMS (ESI-LTQOrbitrap): $m / z$ calcd for $\mathrm{C}_{8} \mathrm{H}_{3} \mathrm{~N}_{6} \mathrm{O}_{3}{ }^{-}[\mathrm{M}-\mathrm{H}]^{-}$231.0272; found 231.0270 .

Generation - two phenolic wedge 9. General procedure of Curtius reaction (method 1) was employed using 5hydroxyisophthalic acid 1 (66 $\mathrm{mg}, 0.362 \mathrm{mmol}, 1.0 \mathrm{eq})$, anhydrous DMF (08 mL), Et $t_{3} \mathrm{~N}(106 \mu \mathrm{L}, 0.760 \mathrm{mmol}, 2.1 \mathrm{eq})$, DPPA (165 $\mu \mathrm{L}, 0.760 \mathrm{mmol}, 2.1 \mathrm{eq})$, and (G1W) ene $(375.2$ $\mathrm{mg}, 0.724 \mathrm{mmol}, 2.0 \mathrm{eq})$ to give a transparent viscous oil as the product $9(22 \mathrm{mg}, 0.018 \mathrm{mmol}, 5 \%)$ after purification (40\% EtOAc/hexane as mobile phase.)

General procedure of Curtius reaction (method 2) was employed using 5-hydroxy-1,3-benzenedicarbonyl diazide 4 (579.3 mg, $2.500 \mathrm{mmol}, 1.0 \mathrm{eq}),($ G1W) ene (1941.5 mg, 3.743 mmol, $1.5 \mathrm{eq})$, and DMF ( $8 \mathrm{~mL})$ to get a transparent viscous oil as the product $9(763.3 \mathrm{mg}, 0.63 \mathrm{mmol}, 34 \%)$ after purification (40\% EtOAc/hexane as mobile phase.) TLC (40\% EtOAc in hexane): $\mathrm{R}_{f} 0.44 .{ }^{1} \mathrm{H} \mathrm{NMR}\left(500 \mathrm{MHz}, \mathrm{CD}_{3} \mathrm{COCD}_{3}\right)$ : $\delta 8.58(\mathrm{t}, 6 \mathrm{H},-\mathrm{NH}-), 8.28(\mathrm{~s}, 1 \mathrm{H}, \mathrm{OH}), 7.29(\mathrm{~s}, 2 \mathrm{H}), 7.20(\mathrm{q}, J$ $=1.9 \mathrm{~Hz}, 1 \mathrm{H}), 6.99(\mathrm{~s}, 4 \mathrm{H}), 6.90(\mathrm{~s}, 2 \mathrm{H}), 5.89-5.84(\mathrm{~m}, 4 \mathrm{H})$, $5.07-4.97(\mathrm{qd}, J=17.1,11.1,9.2,1.7 \mathrm{~Hz}, 8 \mathrm{H}), 4.12(\mathrm{t}, 12 \mathrm{H})$, $3.95(\mathrm{t}, J=6.5 \mathrm{~Hz} 4 \mathrm{H}), 2.19-2.14(\mathrm{~m}, 8 \mathrm{H}), 1.78-1.74(\mathrm{~m}$, 12H), $1.67-1.64(\mathrm{~m}, 4 \mathrm{H}), 1.49-1.46(\mathrm{~m}, 4 \mathrm{H}), 1.43-1.29$ (m, 24H). ${ }^{13} \mathrm{C}$ NMR (125 MHz, $\left.\mathrm{CD}_{3} \mathrm{COCD}_{3}\right): \delta 160.1,158.1$, $153.54,153.51,153.46,140.7,140.6,137.9,114.6,114.5$, $100.7,100.0,99.9,99.2,67.6,64.3,63.7,63.6,61.6,29.8$, 
28.1, 25.9, 25.7. MALDI-TOF-MS (dithranol as matrix): $\mathrm{m} / \mathrm{z}$ calcd for $\mathrm{C}_{66} \mathrm{H}_{96} \mathrm{~N}_{6} \mathrm{O}_{15}[\mathrm{M}+\mathrm{Na}]^{+} 1235.68$, found $[\mathrm{M}+\mathrm{Na}]^{+}$ 1235.67.

Generation two dendron, (G2W) ene. An oven-dried $50 \mathrm{~mL}$ RB flask was charged with 11-bromoundecanol (156.0 mg, $0.620 \mathrm{mmol}, 1.5 \mathrm{eq}), \mathrm{K}_{2} \mathrm{CO}_{3}(285.4 \mathrm{mg}, 2.065 \mathrm{mmol}, 5.0 \mathrm{eq})$, $\mathrm{KI}(13.8 \mathrm{mg}, 0.083 \mathrm{mmol}, 0.2 \mathrm{eq})$, anhydrous acetone $(5 \mathrm{~mL})$, and a magnetic stir bar. After degassing and filling the flask with nitrogen, 9 (501.1 mg, $0.413 \mathrm{mmol}, 1.0 \mathrm{eq})$ in $1.5 \mathrm{~mL}$ anhydrous acetone was transferred into the flask via syringe. The reaction mixture was set to reflux under nitrogen. Progress of reaction was checked with TLC $(3: 2$ hexane/EtOAc). After $20 \mathrm{~h}$, solvent was evaporated, crude was extracted with EtOAc, washed with brine, dried with anhydrous $\mathrm{MgSO}_{4}$, concentrated, and finally purified by flash chromatography using $40 \%$ EtOAc in hexane as mobile phase to give slightly yellow viscous oil as product $(475.5 \mathrm{mg}, 0.344$ mmol, $83 \%$ yield). TLC (40\% EtOAc in hexane): $\mathrm{R}_{f} 0.41 .{ }^{1} \mathrm{H}$ NMR (500 MHz, $\left.\mathrm{CD}_{3} \mathrm{COCD}_{3}\right): \delta 8.58(\mathrm{~d}, 6 \mathrm{H}, \mathrm{NH}), 7.29$ (s, $3 \mathrm{H}), 6.99(\mathrm{~s}, 6 \mathrm{H}), 5.91-5.82(\mathrm{~m}, 4 \mathrm{H}), 5.08-4.97(\mathrm{dq}, J=$ $17.1,10.2,1.5 \mathrm{~Hz}, 8 \mathrm{H}), 4.12$ (q, $J=6.7 \mathrm{~Hz}, 12 \mathrm{H}$, overlapped triplet), $3.95(\mathrm{t}, J=6.5 \mathrm{~Hz}, 6 \mathrm{H}), 3.55(\mathrm{q}, J=18.4,5.7 \mathrm{~Hz}, 2 \mathrm{H})$, $3.40(\mathrm{t}, J=5.3 \mathrm{~Hz} 1 \mathrm{H}, \mathrm{OH}), 2.19-1.80(\mathrm{~m}, J=7.2 \mathrm{~Hz}, 8 \mathrm{H})$, $1.80-1.73(\mathrm{~m}, 16 \mathrm{H}), 1.67-1.63(\mathrm{~m}, J=14.3 \mathrm{~Hz}, 4 \mathrm{H}), 1.53$ $-1.29(\mathrm{~m}, 53 \mathrm{H}) .{ }^{13} \mathrm{C} \mathrm{NMR}\left(125 \mathrm{MHz}, \mathrm{CD}_{3} \mathrm{COCD}_{3}\right): \delta 160.1$, 153.6, 153.5, 140.7, 140.6, 137.9, 114.6, 100.7, 99.2, 67.7, 64.4, 63.7, 61.6, 32.9, 29.8, 281., 25.9, 25.8, 25.7. MALDITOF-MS (dithranol as matrix): $m / z$ calcd for $\mathrm{C}_{77} \mathrm{H}_{118} \mathrm{~N}_{6} \mathrm{O}_{16}$ $[\mathrm{M}+\mathrm{Na}]^{+}$1405.85, found 1405.99.

Surface functionalized generation-two dendron, G2W. General procedure of thiol-ene click reaction was employed using (G2W) ene (101 mg, $0.073 \mathrm{mmol}, 1.0 \mathrm{eq})$, anhydrous DCM $(0.4 \mathrm{~mL}), 1$-octanethiol $(112 \mu \mathrm{L}, 0.584 \mathrm{mmol}, 4.0 \mathrm{eq})$ and AIBN ( $5 \mathrm{mg}, 0.029 \mathrm{mmol}, 0.4 \mathrm{eq}$ ) to give highly viscous, transparent oil as product ( $123.9 \mathrm{mg}, 0.063 \mathrm{mmol}, 86 \%$ yield) after purification (40\% EtOAc/hexane as mobile phase). TLC (30\% EtOAc in hexane): $\mathrm{R}_{f}$ 0.41. ${ }^{1} \mathrm{H}$ NMR $(500 \mathrm{MHz}$, $\left.\mathrm{CD}_{3} \mathrm{COCD}_{3}\right): \delta 8.58(\mathrm{~d}, 6 \mathrm{H}, \mathrm{NH}), 7.28(\mathrm{~s}, 3 \mathrm{H}), 6.99(\mathrm{~s}, 6 \mathrm{H})$, 4.12 (qn, $J=6.5 \mathrm{~Hz}, 12 \mathrm{H}$, overlapped triplet), 3.95 (t, $J=6.5$ $\mathrm{Hz}, 6 \mathrm{H}), 3.55(\mathrm{q}, J=18.4,5.5 \mathrm{~Hz}, 2 \mathrm{H}), 3.39$ (t, $1 \mathrm{H}, J=5.3$ $\mathrm{Hz}, \mathrm{OH}), 2.53$ (q, $J=7.5 \mathrm{~Hz}, 16 \mathrm{H}), 1.77$ (qn, $J=14.4,6 \mathrm{H})$, $1.72-1.25(\mathrm{~m}, 136 \mathrm{H}), 0.89(\mathrm{t}, J=6.9 \mathrm{~Hz}, 12 \mathrm{H}) .{ }^{13} \mathrm{C} \mathrm{NMR}$ $\left(125 \mathrm{MHz}, \mathrm{CD}_{3} \mathrm{COCD}_{3}\right): \delta 160.1,153.60,153.57,160.66$, 140.64, 100.8, 99.2, 67.6, 64.4, 64.2, 61.6, 59.7, 32.9, 31.7, 31.6, 31.4, 25.9, 25.8, 25.7, 25.0, 22.4, 13.6, 13.5. MALDITOF-MS (dithranol as matrix): $m / z$ calcd for $\mathrm{C}_{109} \mathrm{H}_{190} \mathrm{~N}_{6} \mathrm{O}_{16} \mathrm{~S}_{4}$ [M+Na] 1990.30, found 1991.19.

Generation-two dendrimer, G2D. General procedure of attachment of dendron to the core was employed using 1,3,5triisocyanatobenzene 6 ( $7.3 \mathrm{mg}, 0.036 \mathrm{mmol}, 1.0 \mathrm{eq}), \mathbf{G 2 W}$ (233.9 mg, $0.119 \mathrm{mmol}, 3.3 \mathrm{eq}$ ), $\mathrm{BF}_{3} . \mathrm{OEt}_{2}$ (3 drops), and anhydrous DCM $(1.5 \mathrm{~mL})$ to give highly viscous transparent oil as product $(101.3 \mathrm{mg}, 0.017 \mathrm{mmol}, 46 \%$ yield) after purification (30\% EtOAc/hexane as mobile phase). TLC $(30 \%$ EtOAc in hexane): $\mathrm{R}_{f} 0.56 .{ }^{1} \mathrm{H} \mathrm{NMR}\left(500 \mathrm{MHz}, \mathrm{CD}_{3} \mathrm{COCD}_{3}\right)$ : $\delta 8.58(\mathrm{~s}, 21 \mathrm{H}), 7.53(\mathrm{~s}, 3 \mathrm{H}), 7.29(\mathrm{~s}, 9 \mathrm{H}), 6.99(\mathrm{~s}, 18 \mathrm{H}), 4.13$ (s, 42H), $3.94(\mathrm{~s}, 18 \mathrm{H}), 2.52(\mathrm{~d}, J=6.8 \mathrm{~Hz}, 48 \mathrm{H}), 1.76-1.31$ (m, 378H), 0.90 (s, 36H). ${ }^{13} \mathrm{C}$ NMR (125 MHz, $\left.\mathrm{CDCl}_{3}\right): \delta$ $160.3,153.5,139.6,139.5,99.1,68.1,65.4,65.2,32.2,32.0$, $31.8,29.7,29.5,29.4,29.3,29.2,29.1,29.0,28.9,28.6,26.0$, 25.2, 22.7, 14.1. MALDI-TOF-MS (ferulic acid as matrix): $m / z$ calcd for $\mathrm{C}_{336} \mathrm{H}_{573} \mathrm{~N}_{21} \mathrm{O}_{51} \mathrm{~S}_{12}[\mathrm{M}+\mathrm{Na}]^{+}$6125.94, found 6129.89

Generation - three phenolic wedge 10. General procedure of Curtius reaction (method 2) was employed using 5hydroxy-1,3-benzenediacrbonyl diazide 4 (104.9 $\mathrm{mg}, 0.452$ mmol, $1.0 \mathrm{eq}),(\mathbf{G 2 W})_{\text {ene }}(875.4 \mathrm{mg}, 0.633 \mathrm{mmol}, 1.4 \mathrm{eq})$, and anhydrous DMF (5 mL) to give highly viscous transparent oil as product $10(827.7 \mathrm{mg}, 0.270 \mathrm{mmol}, 62 \%$ yield $)$ after purification (40\% EtOAc/hexane as mobile phase). TLC (40\% EtOAc in hexane): $\mathrm{R}_{f} 0.38 .{ }^{1} \mathrm{H} \mathrm{NMR}\left(500 \mathrm{MHz}, \mathrm{CD}_{3} \mathrm{COCD}_{3}\right)$ : $\delta 8.56(\mathrm{~s}, 14 \mathrm{H}, \mathrm{NH}), 8.25(\mathrm{~s}, 1 \mathrm{H}), 7.30(\mathrm{~s}, 6 \mathrm{H}), 7.22(\mathrm{~s}, 1 \mathrm{H})$, $7.00(\mathrm{~s}, 12 \mathrm{H}), 6.92(\mathrm{~s}, 1 \mathrm{H}), 5.89-5.83(\mathrm{~m}, 8 \mathrm{H}), 5.02(\mathrm{dd}, J=$ $17.1,10.2 \mathrm{~Hz}, 16 \mathrm{H}), 4.12(\mathrm{q}, J=6.7 \mathrm{~Hz}, 28 \mathrm{H}), 3.94(\mathrm{t}, J=6.3$ $\mathrm{Hz}, 12 \mathrm{H}), 2.16(\mathrm{q}, J=7.2 \mathrm{~Hz}, 16 \mathrm{H}), 1.80-1.72(\mathrm{~m}, 30 \mathrm{H})$, $1.70-1.60(\mathrm{~m}, 12 \mathrm{H}), 1.50-1.27(\mathrm{~m}, 98 \mathrm{H}) .{ }^{13} \mathrm{C}$ NMR $(125$ $\left.\mathrm{MHz}, \mathrm{CDCOCD}_{3}\right): \delta 160.1,158.2,158.1,153.6,153.5$, $140.65,140.62,137.9,114.6,100.7,100.0,99.9,99.2,67.6$, $64.4,64.3,63.7,29.8,28.1,25.9,25.7$. MALDI-TOF-MS (dithranol as matrix): $\mathrm{m} / z$ calcd for $\mathrm{C}_{162} \mathrm{H}_{240} \mathrm{~N}_{14} \mathrm{O}_{35}[\mathrm{M}+\mathrm{Na}]^{+}$ 2964.73, found 2966.58.

Generation - three dendron, $(\mathbf{G 3 W})_{\text {ene. }}$ The procedure reported for $(\mathbf{G} 2 \mathbf{W})_{\text {ene }}$ was employed using 11bromoundecanol $(68.4 \mathrm{mg}, 0.2721 \mathrm{mmol}, 1.5 \mathrm{eq}), \mathrm{K}_{2} \mathrm{CO}_{3}$ (125.4 mg, $0.907 \mathrm{mmol}, 5.0 \mathrm{eq}), \mathrm{KI}$ (9.0 mg, $0.0544 \mathrm{mmol}$, $0.3 \mathrm{eq}), \mathrm{G} 3$ phenolic wedge $10(534.0 \mathrm{mg}, 0.1814 \mathrm{mmol}, 1.0$ eq), and anhydrous acetone $(8 \mathrm{~mL})$ to give gel-like transparent product $(297.0 \mathrm{mg}, \quad 0.0954 \mathrm{mmol}, \quad 75 \%$ yield $)$ after purification (40\% EtOAc/Hexane as mobile. Phase). TLC (40\% EtOAc in hexane): $\mathrm{R}_{f}$ 0.33. ${ }^{1} \mathrm{H}$ NMR $(500 \mathrm{MHz}$, $\left.\mathrm{CD}_{3} \mathrm{COCD}_{3}\right): \delta 8.60(\mathrm{~d}, J=12.2 \mathrm{~Hz}, 14 \mathrm{H}, \mathrm{NH}), 7.30(\mathrm{~s}, 7)$, $6.99(\mathrm{~s}, 14 \mathrm{H}), 5.91-5.82(\mathrm{~m}, 8 \mathrm{H}), 5.02(\mathrm{dd}, J=17.1,10.1$ $\mathrm{Hz}, 16 \mathrm{H}), 4.12$ (t, $J=6.8,28 \mathrm{H}$, overlapped triplets), 3.94 (t, $J$ $=6.4 \mathrm{~Hz}, 14 \mathrm{H}), 3.55(\mathrm{q}, J=5.7 \mathrm{~Hz}, 2 \mathrm{H}), 3.40(\mathrm{t}, 1 \mathrm{H}, \mathrm{OH})$, $2.16(\mathrm{q}, J=7.2 \mathrm{~Hz}, 16 \mathrm{H}), 1.78-1.72(\mathrm{~m}, 32 \mathrm{H}), 1.69-1.62$ $(\mathrm{m}, 14 \mathrm{H}), 1.50-1.27(\mathrm{~m}, 122 \mathrm{H}) .{ }^{13} \mathrm{C}$ NMR $(125 \mathrm{MHz}$, $\left.\mathrm{CD}_{3} \mathrm{COCD}_{3}\right): \delta 160.1,158.1,153.6,153.5,140.6,137.9$, $114.5,100.7,100.0,99.1,67.6,64.4,64.3,63.7,59.6,29.8$, 29.5, 28.1, 25.9, 25.7. MALDI-TOF-MS (ferulic acid as matrix): $m / z$ calcd for $\mathrm{C}_{173} \mathrm{H}_{262} \mathrm{~N}_{14} \mathrm{O}_{36}[\mathrm{M}+\mathrm{Na}]^{+}$3134.90, found 3136.66 .

Surface functionalized generation-three dendron, G3W. General procedure of thiol-ene click reaction was employed using $(\mathbf{G 3 W})_{\text {ene }}(274.8 \mathrm{mg}, 0.088 \mathrm{mmol}, 1.0 \mathrm{eq})$, 1-octanethiol $(184 \mu \mathrm{L}, 1.059 \mathrm{mmol}, 12.0 \mathrm{eq}$ and $\mathrm{AIBN}$ ( $10 \mathrm{mg}, 0.058$ mmol, $0.8 \mathrm{eq})$, and anhydrous DCM $(1.5 \mathrm{~mL})$ to give gel-like transparent product $(244 \mathrm{mg}, 0.057 \mathrm{mmol}, 65 \%)$ after purification (30\% EtOAc/hexane as mobile phase). TLC (30\% EtOAc in hexane): $\mathrm{R}_{f} 0.58 .{ }^{1} \mathrm{H} \mathrm{NMR}\left(500 \mathrm{MHz}, \mathrm{CD}_{3} \mathrm{COCD}_{3}\right)$ : $\delta 8.58(\mathrm{~d}, J=7.1 \mathrm{~Hz}, 14 \mathrm{H}, \mathrm{NH}), 7.30(\mathrm{~s}, 7 \mathrm{H}), 7.01(\mathrm{~s}, 14 \mathrm{H})$, 4.12 (qn, $J=6.4 \mathrm{~Hz}, 28 \mathrm{H}$, overlapped triplet), 3.94 (t, $J=6.2$ $\mathrm{Hz}, 14 \mathrm{H}), 3.55$ (q, $J=6.1 \mathrm{~Hz}, 2 \mathrm{H}), 3.42(\mathrm{t}, 1 \mathrm{H}, \mathrm{OH}), 2.53$ (q, $J=7.3 \mathrm{~Hz}, 32 \mathrm{H}), 1.80-1.72(\mathrm{~m}, 16 \mathrm{H}), 0.89(\mathrm{t}, J=6.8 \mathrm{~Hz}$, $24 \mathrm{H})$. The large aliphatic multiplet portion was not integrated. ${ }^{13} \mathrm{C}$ NMR $\left(125 \mathrm{MHz}, \mathrm{CD}_{3} \mathrm{COCD}_{3}\right): \delta 160.1,153.6,153.5$, $140.6,100.7,99.1,67.6,64.4,64.3,61.7,32.9,31.7,31.6$, $31.5,29.6,25.9,25.8,25.7,25.0,22.5,13.5$. MALDI-TOFMS (ferulic acid as matrix): $m / z$ calcd for $\mathrm{C}_{237} \mathrm{H}_{406} \mathrm{~N}_{14} \mathrm{O}_{36} \mathrm{~S}_{8}$ $[\mathrm{M}+\mathrm{Na}]^{+}$4303.80, found 4307.95.

Generation-three dendrimer, G3D. General procedure of attachment of dendron to the core was employed using 1,2,3triisocyanatobenzene $\mathbf{6}$ (1.8 $\mathrm{mg}, 0.00918 \mathrm{mmol}, 1.0 \mathrm{eq}), \mathbf{G 3 W}$ (118.0 mg, $0.02754 \mathrm{mmol}, 3.0 \mathrm{eq}), \mathrm{BF}_{3} . \mathrm{OEt}_{2}$ (3 drops), and 
anhydrous DCM (1 mL) to give highly viscous transparent oil as product $(77.9 \mathrm{mg}, 0.0060 \mathrm{mmol}, 65 \%$ yield). TLC (5\% acetone in DCM): $\mathrm{R}_{f} 0.22 .{ }^{1} \mathrm{H}$ NMR $\left(500 \mathrm{MHz}, \mathrm{CD}_{3} \mathrm{COCD}_{3}\right)$ : $\delta 7.27(\mathrm{~s}, 1 \mathrm{H}), 7.05(\mathrm{~s}, 7 \mathrm{H}), 6.80(\mathrm{~s}, 29 \mathrm{H}$, broad), $4.15(\mathrm{~d}, J=$ $5.2 \mathrm{~Hz}, 30 \mathrm{H}$, overlapped triplets), 3.92 (s, 14H, broad triplets), $2.52(\mathrm{q}, J=7.7 \mathrm{~Hz}, 32 \mathrm{H}), 0.90$ (t, $J=13.0 \mathrm{~Hz}, 24 \mathrm{H})$ (large aliphatic hydrocarbon portion was not integrated). ${ }^{13} \mathrm{C}$ NMR (125 MHz, $\mathrm{CD}_{3} \mathrm{COCD}_{3}$ ): $\delta 160.3,153.5$ (broad), 139.54, 139.48, 100.9, 99.9, 69.3, 68.0, 65.4, 65.2, 32.2, 32.0, 31.8, 29.9, 29.7, 29.6, 29.5, 29.4, 29.3, 29.24, 29.21, 29.0, 28.9, 28.6, 26.0, 25.9, 25.2, 22.7, 14.1. MALDI-TOF-MS: unsatisfactory data was obtained even with different matrices like dithranol, ferulic acid, sinapic acid, HABA, HCCA, and DHB.

\section{ASSOCIATED CONTENT}

\section{Supporting Information}

The Supporting Information is available free of charge. ${ }^{1} \mathrm{H} \mathrm{NMR},{ }^{13} \mathrm{C} \mathrm{NMR}, 2 \mathrm{D} \mathrm{NMR}$, and IR spectra as well as mass spectrometric data of the novel compounds described (PDF).

\section{AUTHOR INFORMATION}

\section{Corresponding Author}

Richard T. Taylor - Department of Chemistry and Biochemistry, Miami University, 501 E High St, Oxford, OH 45056, USA

Email: taylorrt@miamioh.edu

\section{Author}

Dhruba P. Poudel - Department of Chemistry and Biochemistry, Miami University, Oxford, $\mathrm{OH} 45056$, USA.

\section{Notes}

The authors declare no competing financial interest.

\section{ACKNOWLEDGMENT}

We acknowledge Department of Chemistry and Biochemistry of Miami University.

\section{REFERENCES}

(1) Sowinska, M.; Urbanczyk-Lipkowska, Z. Advances in the Chemistry of Dendrimers. New J. Chem. 2014, 38 (6), 2168 2203.

(2) Fréchet, J. M. J. Functional Polymers and Dendrimers: Reactivity, Molecular Architecture, and Interfacial Energy. Science (80-. ). 1994, 263 (5154), 1710-1715.

(3) Sandra García-Gallego, M. M. Dendrimer Chemistry: Synthetic Approaches Towards Complex Architectures; Royal Society of Chemistry, Cambridge, 2020; p1-293.

(4) Tomalia, D. A.; Fréchet, J. M. J. Discovery of Dendrimers and Dendritic Polymers: A Brief Historical Perspective. J. Polym. Sci. Part A Polym. Chem. 2002, 40 (16), 2719-2728.

(5) Majoral, J. P.; Mignani, S. M.; Shi, X.; Rodrigues, J. M.; Muñoz-Fernández, M. Á.; Ceña, V.; Roy, R. Dendrimers towards Translational Nanotherapeutics: Concise Key Step Analysis. Bioconjug. Chem. 2020.

(6) Astruc, D.; Chardac, F. Dendritic Catalysts and Dendrimers in Catalysis. Chem. Rev. 2001, 101 (9), 2991-3023.

(7) Watabe, T.; Ishizuki, K.; Aoki, D.; Otsuka, H Mechanochromic Dendrimers: The Relationship between Primary Structure and Mechanochromic Properties in the Bulk. Chem. Commun. 2019, 55 (48), 6831-6834.

(8) Wang, Y.; Zhu, X. Nanofabrication within Unimolecular Nanoreactors. Nanoscale 2020, 12 (24), 12698-12711.
(9) Loch, A. S.; Stoltzfus, D. M.; Burn, P. L.; Shaw, P. E. HighSensitivity Poly(Dendrimer)-Based Sensors for the Detection of Explosives and Taggant Vapors. Macromolecules 2020, 53 (5), 1652-1664.

(10) Lyu, Z.; Ding, L.; Tintaru, A.; Peng, L. Self-Assembling Supramolecular Dendrimers for Biomedical Applications: Lessons Learned from Poly(Amidoamine) Dendrimers. Acc. Chem. Res. 2020, 53 (12), 2936-2949.

(11) Astruc, D.; Boisselier, E.; Ornelas, C. Dendrimers Designed for Functions: From Physical, Photophysical, and Supramolecular Properties to Applications in Sensing, Catalysis, Molecular Electronics, Photonics, and Nanomedicine. Chem. Rev. 2010, 110 (4), 1857-1959.

(12) Ghobril, C.; Rodriguez, E. K.; Nazarian, A.; Grinstaff, M. W. Recent Advances in Dendritic Macromonomers for Hydrogel Formation and Their Medical Applications. Biomacromolecules 2016, 17 (4), 1235-1252.

(13) Sharma, A.; Liaw, K.; Sharma, R.; Spriggs, T.; Appiani La Rosa, S.; Kannan, S.; Kannan, R. M. Dendrimer-Mediated Targeted Delivery of Rapamycin to Tumor-Associated Macrophages Improves Systemic Treatment of Glioblastoma. Biomacromolecules 2020, 21 (12), 5148-5161.

Mignani, S.; Shi, X.; Rodrigues, J.; Roy, R.; Muñoz-Fernández, Á.; Ceña, V.; Majoral, J. P. Dendrimers toward Translational Nanotherapeutics: Concise Key Step Analysis. Bioconjug. Chem. 2020, 31 (9), 2060-2071.

Mignani, S.; Shi, X.; Steinmetz, A.; Majoral, J. P. Multivalent Copper(II)-Conjugated Phosphorus Dendrimers with Noteworthy in Vitro and in Vivo Antitumor Activities: A Concise Overview. Mol. Pharm. 2021, 18 (1), 65-73.

(16) Puttock, E. V.; Ranasinghe, C. S. K.; Babazadeh, M.; Jang, J.; Huang, D. M.; Tsuchiya, Y.; Adachi, C.; Burn, P. L.; Shaw, P. E. Solution-Processed Dendrimer-Based TADF Materials for Deep-Red OLEDs. Macromolecules 2020, 53 (23), 1037510385.

(17) Xu, X.; Zhang, P.; Wu, B.; Xing, Y.; Shi, K.; Fang, W.; Yu, H.; Wang, G. Photochromic Dendrimers for Photoswitched SolidTo-Liquid Transitions and Solar Thermal Fuels. ACS Appl. Mater. Interfaces 2020, 12 (44), 50135-50142.

(18) Wang, X. Q.; Wang, W.; Li, W. J.; Chen, L. J.; Yao, R.; Yin, G. Q.; Wang, Y. X.; Zhang, Y.; Huang, J.; Tan, H.; Yu, Y.; Li, X.; Xu, L.; Yang, H. B. Dual Stimuli-Responsive RotaxaneBranched Dendrimers with Reversible Dimension Modulation. Nat. Commun. 2018, 9 (1), 1-11.

(19) Takeda, S.; Nishimura, T.; Umezaki, K.; Kubo, A.; Yanase, M.; Sawada, S. I.; Sasaki, Y.; Akiyoshi, K. Synthesis and Function of Amphiphilic Glucan Dendrimers as Nanocarriers for Protein Delivery. Biomater. Sci. 2019, 7 (4), 1617-1622.

(20) Tomalia, D. A.; Baker, H.; Hall, M.; Kallos, G.; Martin, S.; Ryder, J.; Smith, P. Dendritic Macromolecules:1 Synthesis of Starburst Dendrimers. Macromolecules 1986, 19 (9), 2466-

(21) Zhang, Y.; Üçüncü, M.; Gambardella, A.; Baibek, A.; Geng, J.; Zhang, S.; Clavadetscher, J.; Litzen, I.; Bradley, M.; Lilienkampf, A. Bioorthogonal Swarming: In Situ Generation of Dendrimers. J. Am. Chem. Soc. 2020, 142 (52), 21615 21621.

(22) Milenin, S. A.; Cherkaev, G. V.; Demchenko, N. V.; Serkova, E. S.; Krasnova, I. Y.; Selezneva, E. V.; Buzin, M. I.; Bakirov, A. V.; Vasil'ev, V. G.; Shifrina, Z. B.; Chvalun, S. N.; Muzafarov, A. M. Influence of the Growing Flexible Shell on the Molecular Behavior of Hybrid Dendrimers. Macromolecules 2020, 53 (22), 9706-9716.

(23) Malkoch, M. Introduction to Dendrimers ans Other Dendritic Polymers. 2020, No. 29, 1-20.

(24) Li, W. J.; Hu, Z.; Xu, L.; Wang, X. Q.; Wang, W.; Yin, G. Q.; Zhang, D. Y.; Sun, Z.; Li, X.; Sun, H.; Yang, H. B. RotaxaneBranched Dendrimers with Enhanced Photosensitization. $J$. Am. Chem. Soc. 2020, 142 (39), 16748-16756.

(25) Kaufman, E. A.; Tarallo, R.; Elacqua, E.; Carberry, T. P.; Weck, M. Synthesis of Well-Defined Bifunctional NewkomeType Dendrimers. Macromolecules 2017, 50 (13), 4897-4905.

(26) Farabi, K.; Manabe, Y.; Ichikawa, H.; Miyake, S.; Tsutsui, M.; Kabayama, K.; Yamaji, T.; Tanaka, K.; Hung, S. C.; Fukase, K. Concise and Reliable Syntheses of Glycodendrimers via SelfActivating Click Chemistry: A Robust Strategy for Mimicking 
Multivalent Glycan-Pathogen Interactions. J. Org. Chem. 2020 85 (24), 16014-16023.

(27) Molina, N.; Nájera, F.; Guadix, J. A.; Perez-Pomares, J. M.; Vida, Y.; Perez-Inestrosa, E. Synthesis of Amino Terminal Clicked Dendrimers. Approaches to the Application as a Biomarker. J. Org. Chem. 2019, 84 (16), 10197-10208.

(28) Sharma, R.; Kottari, N.; Chabre, Y. M.; Abbassi, L.; Shiao, T. C.; Roy, R. A Highly Versatile Convergent/Divergent "Onion Peel" Synthetic Strategy toward Potent Multivalent Glycodendrimers. Chem. Commun. 2014, 50 (87), 13300 13303.

(29) Thomas, B.; Pifferi, C.; Daskhan, G. C.; Fiore, M.; Berthet, N.; Renaudet, O. Divergent and Convergent Synthesis of GalNAcConjugated Dendrimers Using Dual Orthogonal Ligations. Org. Biomol. Chem. 2015, 13 (47), 11529-11538.

(30) Stadler, A. M. Structural Features of Fréchet-Type Dendrons and Dendrimers in Single Crystals. Cryst. Growth Des. 2010, 10 (12), 5050-5065.

(31) Agrahari, A. K.; Singh., A. S.; Mukherjee, R.; Tiwari, V. K. An Expeditious Click Approach towards the Synthesis of Galactose Coated Novel Glyco-Dendrimers and Dentromers Utilizing a Double Stage Convergent Method. RSC Adv. 2020, 10 (52), 31553-31562.

(32) El Hankari, S.; Katir, N.; Collière, V.; Coppel, Y.; Bousmina, M.; Majoral, J. P.; El Kadib, A. Urea-Assisted Cooperative Assembly of Phosphorus Dendrimer-Zinc Oxide Hybrid Nanostructures. New J. Chem. 2019, 43 (5), 2141-2147.

(33) Zhou, H. Y.; Zong, Q. S.; Han, Y.; Chen, C. F. Recent Advances in Higher Order Rotaxane Architectures. Chem. Commun. 2020, 56 (69), 9916-9936.

(34) Bruchmann, B. Dendritic Polymers Based on Urethane Chemistry - Syntheses and Applications. Macromol. Mater. Eng. 2007, 292 (9), 981-992.

(35) Etcalf, R. O. L. M. General Info of Isocyanates and Their Handling. Ullmann's Encycl. Ind. Chem. 2012, 264-322.

(36) Spindler, R.; Fréchet, J. M. J. Synthesis and Characterization of Hyperbranched Polyurethanes Prepared from Blocked Isocyanate Monomers by Step-Growth Polymerization.

(37) Spindler, R.; Fréchet, J. M. J. Two-Step Approach towards the Accelerated Synthesis of Dendritic Macromolecules. J. Chem. Soc. Perkin Trans. 1 1993, No. 8, 913-918.

(38) Kumar, A.; Ramakrishnan, S. A Novel One-Pot Synthesis of Hyperbranched Polyurethanes. J. Chem. Soc. Chem. Commun. 1993, No. 18, 1453-1454.

(39) Newkome, G. R.; Yao, Z. Q.; Baker, G. R.; Gupta, V. K. Cascade Molecules: A New Approach to Micelles.1aA [27]Arborol. J. Org. Chem. 1985, 50 (11), 2003-2004.

(40) Stoddart, A.; Feast, W. J.; Rannard, S. P. Synthesis and Thermal Studies of Aliphatic Polyurethane Dendrimers: A Geometric Approach to the Flory-Fox Equation for Dendrimer Glass Transition Temperature. Soft Matter 2012, 8 (4), 1096-1108.

(41) Clark, A. M.; Echenique, J.; Haddelton, D. M.; Straw, T. A.; Taylor, P. C. A Nonisocyanate Route to Monodisperse Branched Polyurethanes. J. Org. Chem. 2001, 66, 8687-8689.

(42) Goodwin, A. P.; Lam, S. S.; Fréchet, J. M. J. Rapid, Efficient Synthesis of Heterofunctional Biodegradable Dendrimers. $J$. Am. Chem. Soc. 2007, 129, 6994-6995.

(43) Rannard, S. P.; Davis, N. J.; Herbert, I. Synthesis of Water Soluble Hyperbranched Polyurethanes Using Selective Activation of $\mathrm{AB}_{2}$ Monomers. Macromolecules 2004, 37, 9418 - 9430.

(44) Peerlings, H. W. I.; Van Benthem, R. A. T. M.; Meijer, E. W. Fast and Convenient Construction of Carbamate/Urea-Based Dendrimers with a Diisocyanate Building Block. J. Polym. Sci. Part A Polym. Chem. 2001, 39 (18), 3112-3120.

(45) Tong, Q. S.; Xu, W.; Huang, Q. Y.; Zhang, Y. R.; Shi, X. X.; Huang, H.; Li, H. J.; Du, J. Z.; Wang, J. Multi-Stimuli Responsive Poly(Amidoamine) Dendrimers with Peripheral: N -Dialkylaminoethyl Carbamate Moieties. Polym. Chem. 2019, $10(5), 656-662$.

(46) Abdelrehim, M.; Komber, H.; Langenwalter, J.; Voit, B.; Bruchmann, B. Synthesis and Characterization of Hyperbranched Poly(Urea-Urethane)s Based on AA* and B2B* Monomers. J. Polym. Sci. Part A Polym. Chem. 2004, 42 (12), 3062-3081.
Gomez, I. J.; Arnaiz, B.; Cacioppo, M.; Arcudi, F.; Prato, M. Nitrogen-Doped Carbon Nanodots for Bioimaging and Delivery of Paclitaxel. J. Mater. Chem. B 2018, 6 (35).

Mohamad Ali, B.; Velavan, B.; Sudhandiran, G.; Sridevi, J.; Sultan Nasar, A. Radical Dendrimers: Synthesis, Anti-Tumor Activity and Enhanced Cytoprotective Performance of TEMPO Free Radical Functionalized Polyurethane Dendrimers. Eur. Polym. J. 2020, 122 (August 2019), 109354.

(49) Ashok Kumar, K.; Sultan Nasar, A.; Mohamad Ali, B; Bargathulla, I.; Sathiyaraj, S. Elimination of 50\% Iodine and Excellent Performance of Dye-Sensitized Solar Cell Enabled by Tempo Radical Dendrimer-iodide Dual Redox Systems. ACS Appl. Energy Mater. 2020, 3 (11), 10506-10514.

(50) Sathiyaraj, S.; Kumar, K. A.; Jailani Shanavas, A. K.; Sultan Nasar, A. S. The First Example of Bisindole-Based Polyurethane Dendrimers: Synthesis and Performance in DSSC. ChemistrySelect 2017, 2 (24), 7108-7116.

(51) Matsumura, S.; Hlil, A. R.; Lepiller, C.; Gaudet, J.; Guay, D.; Shi, Z.; Holdcroft, S.; Hay, A. S. Stability and Utility of Pyridyl Disulfide Functionality in RAFT and Conventional Radical Polymerizations. J. Polym. Sci. Part A Polym. Chem. 2008, 46 (April), 7207-7224.

(52) Veerapandian, S.; Amudha, S.; Suthanthiraraj, S. A.; Rahman, M. A.; Nasar, A. S. Enhanced Performance of a Nanocrystalline Dye-Sensitized Solar Cell Based on Polyurethane Dendrimers. RSC Adv. 2015, 5 (40), 31404-31409.

(53) Grayson, S. M.; Fréchet, J. M. J. Convergent Dendrons and Dendrimers. Chem. Rev. 2001, 101, 3819-3867.

(54) Hawker, C. J.; Fréchet, J. M.J. Preparation of Polymers with Controlled Molecular Architecture. A New Convergent Approach to Dendritic Macromolecules. J. Am. Chem. Soc. 1990, 112, 21, 7638 - 7647.

(55) Kowalczyk, W.; Mascaraque, A.; Sánchez-Navarro, M.; Rojo, J.; Andreu, D. Convergent Synthesis of Glycodendropeptides by Click Chemistry Approaches. European J. Org. Chem. 2012, No. 24, 4565-4573.

(56) López-Méndez, L. J.; Cuéllar-Ramírez, E. E.; CabreraQuiñones, N. C.; Rojas-Aguirre, Y.; Guadarrama, P. Convergent Click Synthesis of Macromolecular Dendritic $\beta$ Cyclodextrin Derivatives as Non-Conventional Drug Carriers: Albendazole as Guest Model. Int. J. Biol. Macromol. 2020, 164, 1704-1714.

(57) Moreno, P.; Quéléver, G.; Peng, L. Synthesis of Poly(Aminoester) Dendrimers via "click" Chemistry in Combination with the Divergent and Convergent Strategies. Tetrahedron Lett. 2015, 56 (26), 4043-4046.

(58) Golshan, M.; Rostami-Tapeh-Esmail, E.; Salami-Kalajahi, M.; Roghani-Mamaqani, H. A Review on Synthesis, Photophysical Properties, and Applications of Dendrimers with Perylene Core. Eur. Polym. J. 2020, 137 (June), 109933.

(59) Wang, L.; Kiemle, D. J.; Boyle, C. J.; Connors, E. L.; Gitsov, I. "Click" Synthesis of Intrinsically Hydrophilic Dendrons and Dendrimers Containing Metal Binding Moieties at Each Branching Unit. Macromolecules 2014, 47 (7), 2199-2213.

(60) Sehad, C.; Shiao, T. C.; Sallam, L. M.; Azzouz, A.; Roy, R. Effect of Dendrimer Generation and Aglyconic Linkers on the Binding Properties of Mannosylated Dendrimers Prepared by a Combined Convergent and Onion Peel Approach. Molecules 2018, 23 (8).

(61) Meyhoff, U.; Riber, U.; Boas, U. Convergent Synthesis of Degradable Dendrons Based on L-Malic Acid. New J. Chem. 2015, 39 (2), 1161-1171. https://doi.org/10.1039/c4nj01156b.

(62) Guizzardi, R.; Vacchini, M.; Santambrogio, C.; Cipolla, L. Convergent Dendrimer Synthesis by Olefin Metathesis and Studies toward Glycoconjugation. Can. J. Chem. 2017, 95 (9), 1008-1012.

(63) Bondareva, J.; Kolotylo, M.; Rozhkov, V.; Burilov, V.; Lukin, O. A Convergent Approach to Sulfonimide-Based Dendrimers and Dendrons. Tetrahedron Lett. 2020, 61 (25), 152011.

(64) Ray, A.; Khan, S. Convergent Synthesis of Novel Mono- and Di-Substituted 1,2-Isopropylideneglucofuranose Appended Dendrimers with a Ferrocene Core and Their Electrochemical Studies. Synlett 2018, 29 (10), 1367-1372.

(65) Miller, T. M.; Neenan, T. X. Convergent Synthesis of Monodisperse Dendrimers Based upon 1,3,5-Trisubstituted 

Synthesis of Polyimide Dendrimers from an ABB' Intermediate. Adv. Mater. Res. 2013, 716, 438-442.

(67) Enciso, A. E.; Abid, Z. M.; Simanek, E. E. Rapid, SemiAutomated Convergent Synthesis of Low Generation Triazine Dendrimers Using Microwave Assisted Reactions. Polym. Chem. 2014, 5 (16), 4635-4640.

(68) Han, S. C.; Kim, J. H.; Lee, J. W. Convergent Synthesis of PAMAM Dendrimers Containing Tetra(Ethyleneoxide) at Core Using Click Chemistry. Bull. Korean Chem. Soc. 2012, 33 (10), 3501-3504.

(69) Akiyama, H.; Miyashita, K.; Hari, Y.; Obika, S.; Imanishi, T. Synthesis of Novel Polyesteramine Dendrimers by Divergent and Convergent Methods. Tetrahedron 2013, 69 (33), 68106820 .

(70) Joosten, A.; Schneider, J. P.; Lepage, M. L.; Tarnus, C.; Bodlenner, A.; Compain, P. A Convergent Strategy for the Synthesis of Second-Generation Iminosugar Clusters Using "Clickable" Trivalent Dendrons. European J. Org. Chem. 2014, 2014 (9), 1866-1872.

(71) Laurent, B. A.; Grayson, S. M. Synthesis of Cyclic Dendronized Polymers via Divergent "Graft- from" and Convergent Click "Graft-to" Routes: Preparation of Modular Toroidal Macromolecules. J. Am. Chem. Soc. 2011, 133 (34), 13421-13429.

(72) Jee, J. A.; Spagnuolo, L. A.; Rudick, J. G. Convergent Synthesis of Dendrimers via the Passerini Three-Component Reaction. Org. Lett. 2012, 14 (13), 3292-3295.

(73) Feast, W. J.; rannard, S. P.; Stoddart, A. Selective Convergent Synthesis of Aliphatic Polyurethane Dendrimers. Macromolecules, 2003, 36, 9704-9706.

(74) Feast, W. J.; Rannard, S. P.; Stoddart, A. Selective Convergent Synthesis of Aliphatic Polyurethane Dendrimers Macromolecules 2003, 36 (26), 9704-9706.

(75) Reemers, S.; Mourran, A.; Keul, H.; Möller, M. Novel Route to Dendritic Structures and Their Application for Surface Modification. J. Polym. Sci. Part A Polym. Chem. 2006, 44 (4), 1372-1386.

(76) Hoyle, C. E.; Bowman, C. N. Thiol-Ene Click Chemistry. Angew. Chemie - Int. Ed. 2010, 49 (9), 1540-1573.

(77) Dondoni, A. The Emergence of Thiol-Ene Coupling as a Click Process for Materials and Bioorganic Chemistry. Angew. Chemie - Int. Ed. 2008, 47 (47), 8995-8997.

(78) Sharma, A.; Sharma, R.; Zhang, Z.; Liaw, K.; Kambhampati, S. P.; Porterfield, J. E.; Lin, K. C.; DeRidder, L. B.; Kannan, S.; Kannan, R. M. Dense Hydroxyl Polyethylene Glycol Dendrimer Targets Activated Glia in Multiple CNS Disorders. Sci. Adv. 2020, 6 (4), 1-15.

(79) Montañez, M. I.; Campos, L. M.; Antoni, P.; Hed, Y.; Walter, M. V.; Krull, B. T.; Khan, A.; Hult, A.; Hawker, C. J.; Malkoch, M. Accelerated Growth of Dendrimers via Thiol-Ene and Esterification Reactions. Macromolecules 2010, 43 (14), 6004 6013.

(80) Fuentes-Paniagua, E.; Hernández-Ros, J. M.; Sánchez-Milla, M.; Camero, M. A.; Maly, M.; Pérez-Serrano, J.; Copa-Patiño, J. L.; Sánchez-Nieves, J.; Soliveri, J.; Gómez, R.; Javier De La Mata, F. Carbosilane Cationic Dendrimers Synthesized by Thiol-Ene Click Chemistry and Their Use as Antibacterial Agents. RSC Adv. 2014, 4 (3), 1256-1265.

(81) Bi, X.; Liang, A.; Tan, Y.; Maturavongsadit, P.; Higginbothem, A.; Gado, T.; Gramling, A.; Bahn, H.; Wang, Q. Thiol-Ene Crosslinking Polyamidoamine Dendrimer-Hyaluronic Acid Hydrogel System for Biomedical Applications. J. Biomater. Sci. Polym. Ed. 2016, 27 (8), 743-757.

(82) Sharma, R.; Zhang, I.; Shiao, T. C.; Pavan, G. M.; Maysinger, D.; Roy, R. Low Generation Polyamine Dendrimers Bearing Flexible Tetraethylene Glycol as Nanocarriers for Plasmids and SiRNA. Nanoscale 2016, 8 (9), 5106-5119.

(83) Kaya, N. U.; Du Prez, F. E.; Badi, N. Multifunctional Dendrimer Formation Using Thiolactone Chemistry. Macromol. Chem. Phys. 2017, 218 (18), 1-8.

(84) Bagul, R. S.; Hosseini, M. M.; Shiao, T. C.; Roy, R. "Onion Peel" Glycodendrimer Syntheses Using Mixed Triazine and Cyclotriphosphazene Scaffolds. Can. J. Chem. 2017, 95 (9),
975-983.

(85) Granskog, V.; Andrén, O. C. J.; Cai, Y.; González-Granillo, M.; Felländer-Tsai, L.; Von Holst, H.; Haldosen, L. A.; Malkoch, M. Linear Dendritic Block Copolymers as Promising Biomaterials for the Manufacturing of Soft Tissue Adhesive Patches Using Visible Light Initiated Thiol-Ene Coupling Chemistry. Adv. Funct. Mater. 2015, 25 (42), 6596-6605.

(86) Han, Y.; Zhou, X.; Qian, Y.; Hu, H.; Zhou, Z.; Liu, X.; Tang, J.; Shen, Y. Hypoxia-Targeting Dendritic MRI Contrast Agent Based on Internally Hydroxy Dendrimer for Tumor Imaging. Biomaterials 2019, 213 (May), 119195.

(87) Zhang, Y.; Andrén, O. C. J.; Nordström, R.; Fan, Y.; Malmsten, M.; Mongkhontreerat, S.; Malkoch, M. Off-Stoichiometric Thiol-Ene Chemistry to Dendritic Nanogel Therapeutics. $A d v$. Funct. Mater. 2019, 29 (18).

(88) Zhang, J.; Liu, C.; Cheng, J.; Miao, M.; Zhang, D. Simultaneous Toughening and Strengthening of Diglycidyl Ether of Bisphenol-a Using Epoxy-Ended Hyperbranched Polymers Obtained from Thiol-Ene Click Reaction. Polym. Eng. Sci. 2018, 58 (10), 1703-1709.

(89) Hoff, E. A.; De Hoe, G. X.; Mulvaney, C. M.; Hillmayer, M. A.; Alabi, C. A. Thiol-Ene Networks from Sequence-Defined Polyurethane Macromers. J. Am. Chem. Soc. 2020, 43, 60046013.

(90) Soiberman, U.; Kambhampati, S. P.; Wu, T.; Mishra, M. K.; Oh, Y.; Sharma, R.; Wang, J.; Al Towerki, A. E.; Yiu, S.; Stark, W. J.; Kannan, R. M. Subconjunctival Injectable DendrimerDexamethasone Gel for the Treatment of Corneal Inflammation. Biomaterials 2017, 125, 38-53.

(91) Aoki, K.; Imanishi, R.; Yamada, M. Novel Dendritic Polyenes for Application to Tailor-Made Thiol-Ene Photopolymers with Excellent UV-Curing Performance. Prog. Org. Coatings 2016, 100, 105-110. https://doi.org/10.1016/j.porgcoat.2016.01.024.

(92) Quintana, S.; García, M. Á.; Marina, M. L.; Gómez, R.; de la Mata, F. J.; Ortega, P. Synthesis of Chiral Carbosilane Dendrimers with L-Cysteine and N-Acetyl-L-Cysteine on Their Surface and Their Application as Chiral Selectors for Enantiomer Separation by Capillary Electrophoresis. Tetrahedron Asymmetry 2017, 28 (12), 1797-1802.

(93) Naguib, H.; Cao, X.; Gao, H. Synthesize Hyperbranched Polymers Carrying Two Reactive Handles via CuAAC Reaction and Thiol-Ene Chemistry. Macromol. Chem. Phys. 2019, 220 (17), 1-7.

(94) Wang, J.; Cooper, R. C.; Yang, H. Polyamidoamine Dendrimer Grafted with an Acid-Responsive Charge-Reversal Layer for Improved Gene Delivery. Biomacromolecules 2020, 21 (10), 4008-4016.

(95) Ortega, P.; Gómez, R.; De La Mata, F. J. Thiol Ended Carbosilane Dendrimers. A Multivalent Platform for the Binding of Molecules of Biological Interest. Tetrahedron Lett. 2015, 56 (38), 5299-5302.

(96) Rissing, C.; Son, D. Y. Application of Thiol - Ene Chemistry to the Preparation of Carbosilane - Thioether Dendrimers. Organometallics 2009, 28, 3167-3172.

(97) Zhang, Z.; Feng, S.; Zhang, J. Facile and Efficient Synthesis of Carbosiloxane Dendrimers via Orthogonal Click Chemistry between Thiol and Ene. Macromol. Rapid Commun. 2016, 37 (4), 318-322.

(98) Cakir, N.; Tunca, U.; Hizal, G.; Durmaz, H. Heterofunctionalized Multiarm Star Polymers via Sequential Thiol-Para-Fluoro and Thiol-Ene Double "Click" Reactions. Macromol. Chem. Phys. 2016, 217 (5), 636-645.

(99) Kaga, S.; Gevrek, T. N.; Sanyal, A.; Sanyal, R. Synthesis and Functionalization of Dendron-Polymer Conjugate Based Hydrogels via Sequential Thiol-Ene "Click" Reactions. $J$. Polym. Sci. Part A Polym. Chem. 2016, 54 (7), 926-934.

(100) Antoni, P.; Robb, M. J.; Campos, L.; Montanez, M.; Hult, A.; Malmström, E.; Malkoch, M.; Hawker, C. J. Pushing the Limits for Thiol-Ene and CuAAC Reactions: Synthesis of a 6th Generation Dendrimer in a Single Day. Macromolecules 2010, 43 (16), 6625-6631.

(101) Conte, M. Lo; Robb, M. J.; Hed, Y.; Marra, A.; Malkoch, M.; Hawker, C. J.; Dondoni, A. Exhaustive Glycosylation, Pegylation, and Glutathionylation of a [G4]-Ene48 Dendrimer via Photoinduced Thiol-Ene Coupling. J. Polym. Sci. Part A 
Polym. Chem. 2011, 49 (20), 4468-4475.

(102) Fuentes-Paniagua, E.; Peña-González, C. E.; Galán, M.; Gómez, R.; De La Mata, F. J.; Sánchez-Nieves, J. Thiol-Ene Synthesis of Cationic Carbosilane Dendrons: A New Family of Synthons. Organometallics 2013, 32 (6), 1789-1796.

(103) Robb, M. J.; Hawker, C. J. "Click" Chemistry in Polymer Science: CuAAC and Thiol-Ene Coupling for the Synthesis and Functionalization of Macromolecules. Mater. Sci. Technol. 2012, 923-972.

(104) Sharma, R.; Naresh, K.; Chabre, Y. M.; Rej, R.; Saadeh, N. K.; Roy, R. Onion Peel Dendrimers: A Straightforward Synthetic Approach towards Highly Diversified Architectures. Polym. Chem. 2014, 5 (14), 4321-4331.

(105) Ghirardello, M.; Öberg, K.; Staderini, S.; Renaudet, O.; Berthet, N.; Dumy, P.; Hed, Y.; Marra, A.; Malkoch, M.; Dondoni, A. Thiol-Ene and Thiol-Yne-Based Synthesis of Glycodendrimers as Nanomolar Inhibitors of Wheat Germ Agglutinin. J. Polym. Sci. Part A Polym. Chem. 2014, 52 (17), 2422-2433.

(106) Galán, M.; Sánchez Rodríguez, J.; Jiménez, J. L.; Relloso, M.; Maly, M.; De La Mata, F. J.; Muñoz-Fernández, M. A.; Gómez, R. Synthesis of New Anionic Carbosilane Dendrimers via Thiol-Ene Chemistry and Their Antiviral Behaviour. Org. Biomol. Chem. 2014, 12 (20), 3222-3237.

(107) Kottari, N.; Chabre, Y. M.; Shiao, T. C.; Rej, R.; Roy, R. Efficient and Accelerated Growth of Multifunctional Dendrimers Using Orthogonal Thiol-Ene and SN2 Reactions. Chem. Commun. 2014, 50 (16), 1983-1985.

(108) Jeong, H. J.; Kim, B. K. Shape Memory Hyperbranched Polyurethanes via Thiol-Ene Click Chemistry. React. Funct. Polym. 2017, 116 (February), 92-100.

(109) Han, W. Application of Thiol-Ene "Click" Chemistry to Preparation of Hyperbranched Polyurethane Acrylate Oligomers Containing Carboxyl Groups. J. Photopolym. Sci. Technol. 2015, 28 (3), 419-427.

(110) Puapaiboon, U.; Taylor, R. T. Characterization and Monitoring
Reaction of Polyurethane Dendritic Wedges and Dendrimers Using Matrix-Assisted Laser Desorption/Ionization Time-ofFlight Mass Spectrometry. Rapid Commun. Mass Spectrom. 1999, 13 (6), 508-515.

(111) Taylor, R. T.; Puapaiboon, U. Polyurethane Dendrimers via Curtius Reaction. Tetrahedron Lett. 1998, 39 (44), 8005-8008.

(112) Ghosh, A. K.; Sarkar, A.; Brindisi, M. The Curtius Rearrangement: Mechanistic Insight and Recent Applications in Natural Product Syntheses. Org. Biomol. Chem. 2018, 16 (12), 2006-2027.

(113) Ghosh, A. K.; Brindisi, M.; Sarkar, A. The Curtius Rearrangement: Applications in Modern Drug Discovery and Medicinal Chemistry. ChemMedChem 2018, 13 (22), 23512373.

(114) Hou, X.; Butz, J.; Chen, J.; Wang, Z. D.; Zhao, J. X.; Shiu, T.; Chu, Q. R. Low Molecular Weight Organogelators Derived from Threefold Symmetric Tricarbamates. Tetrahedron Lett. 2017, 58 (1), 101-105.

(115) Zhu, M.; Hao, N.; Zaheer, M.; Yang, J.; Li, L. Preparation of Functional Long-Subchain Hyperbranched Polystyrenes via Post-Polymerization Modification: Study on the Critical Role of Chemical Stability of Branching Linkage. ChemistryOpen 2020, 9 (9), 967-974.

(116) Lindhorst, T. K.; Elsner, K. Postsynthetic Functionalization of Glycodendrons at the Focal Point. Beilstein J. Org. Chem. 2014, 10, 1482-1487.

(117) Lowe, A. B. Thiol-Ene "Click" Reactions and Recent Applications in Polymer and Materials Synthesis. Polym. Chem. 2010, 1 (1), 17-36.

(118) Poudel, D. P.; Taylor, R. T. A Model for Late-Stage Modification of Polyurethane Dendrimers Using Thiol-Ene Click Chemistry. ACS Omega 2021, doi.10.1021/acsomega.1c01609. 